\title{
Mechanical performance of additively manufactured pure silver antibacterial bone scaffolds
}

\author{
Arun Arjunan ${ }^{*}$, John Robinson ${ }^{1,2}$, Enas Al Ani ${ }^{3}$, Wayne Heaselgrave ${ }^{3}$, Ahmad Baroutaji ${ }^{1}$, Chang Wang ${ }^{4}$ \\ ${ }^{1}$ School of Engineering, University of Wolverhampton, Telford Innovation Campus, Telford TF2 9NT, UK \\ ${ }^{2} 6 \mathrm{DME}$ Ltd., Stirchley Road, Telford TF3 1EB, UK \\ ${ }^{3}$ School of Biology, Chemistry and Forensic Science, University of Wolverhampton, Wulfruna St, WV1 1LY, UK \\ ${ }^{4}$ Department of Engineering and Design, University of Sussex, Brighton BN1 9RH, United Kingdom
}

\begin{abstract}
Implant infection is a serious complication resulting in pain, mortality, prolonged recovery, and antimicrobial resistance (AMR). Reducing the risk-of-infection associated with tissue implants require imminent attention, where pure silver $(\mathrm{Ag})$ offers enormous potential. However, the printability, mechanical performance nor microbial resistance of additively manufactured (AM) pure $\mathrm{Ag}$ is unavailable in literature. This is critical as Ag is thought to play a vital role in the development of AM patient-specific infection resistant implants in the decade to come. The study therefore additively manufactured $99.9 \%$ pure-Ag through selective laser melting (SLM) and systematically investigates its mechanical performance. The validated SLM process parameters were then used to conceive two fully porous bone scaffold each at approximately 68 and $90 \%$ (wt.) porosity. While the study brings to attention the potential defects in SLM pure-Ag through X-ray nanotomography (Xray $\mathrm{nCT}$ ), the mechanical properties of porous $\mathrm{Ag}$ scaffolds were found to be similar to cancellous bone. The study achieved the highest SLM pure-Ag density of $97 \%$ with Young's modulus $(\mathrm{E})$, elastic limit $\left(\sigma_{e}\right)$, yield strength $\left(\sigma_{y}\right)$, ultimate strength $\left(\sigma_{u l t}\right)$ and ultimate strain $\left(\varepsilon_{u l t}\right)$ in the range of $15.5-17.8 \mathrm{GPa}, 50.7-57.7 \mathrm{MPa}, 57.6-$ 67.2 MPa, 82.4-95.9 $\mathrm{MPa}$ and 0.07-0.10 respectively. The antimicrobial efficacy of printed silver was tested against the common implant infection-causing Staphylococcus aureus and led to $90 \%$ and $99.9 \%$ kill in 4 and 14 hours respectively. The study, therefore, is a first step towards achieving a new generation Ag-based AM infection resistant porous implants.
\end{abstract}

Keywords: Additive Manufacturing; Selective Laser Melting; Bone scaffold; Pure Silver; Antibacterial; Mechanical Performance

\footnotetext{
${ }^{*}$ Corresponding author. Address: School of Engineering, Faculty of Science and Engineering, University of Wolverhampton, Telford Campus, Shifnal Road, Priorslee, Telford, TF2 9NT, UK. Tel.: +44 (0)1902 323829; fax: +44 (0)1902 323843.

E-mail address: a.arjunan@wlv.ac.uk (Arun Arjunan).
} 


\section{Introduction}

Millions of people across the world suffer from inflammatory and degenerative diseases associated with bone and joints [1,2]. According to the review by Ribeiro et al. [3], a significant percentage of all chronic diseases in people over the age of 50 in developed countries fall under this category. Navarro et al. [4] predict that the number of people affected by bone diseases and requiring invasive surgeries will double in the next decade. Despite the substantial advances in invasive surgery and aseptic techniques, implant-related infection remains an all too common complication [5]. O'Cearbhaill [6] suggested that even systematically introduced antibiotics were largely ineffective for peri-implant infections leading to life-threatening complications. This is primarily due to antibiotic resistance, insufficient drug penetration, and suboptimal bioavailability at the implant site. Once the infection takes hold, the implant needs removal, followed by the resection of the infected tissue. The surrounding tissue must then be treated with antibacterial agents before a surgical revision can be performed. Overall, implant-related infection accounts for extremely high healthcare costs and long recovery time adding to the economic burden estimated by Kurtz et al. [7] to be around $\$ 1.62$ billion in the US alone by 2020.

As a response from the research community, multifunctional bone scaffolds that offer protection against infections were being intensively investigated [8-13]. The use of additive manufacturing (AM) for the digital fabrication of permeable implants loaded with antibiotics that can be released into the infected sites was one option being considered [14-17]. Studies conducted by Krakhmalev et al. [18] and Macpherson et al. [19] identifies the possibility to infuse antibacterial metals to reduce infection. Other notable strategies include the development of bespoke surface coatings [20,21] to achieve infection resistance as reviewed by Chouirfa et al. [22] and Orapiriyakul et al. [23]. Some of these strategies have been applied by Vaithilingam et al. [24] and Zhang et al. [25] to porous AM titanium (Ti) based implants for antimicrobial incorporation.

A proportion of literature has also been dedicated to implant surface coatings that featuring metallic ions such as silver (Ag) [26-30], zinc (Zn) [31-34], copper ( $\mathrm{Cu})$ [19,35-37] and lithium (Li) [38-40] for the reduction of implant infection. The use of metallic ions as infection resistant agents was being increasingly investigated as a result of wide-spectrum antimicrobial properties [41]. Metallic ions were also favoured over targeted antibiotic delivery due to the growing concerns over antibiotic resistance. Among the different metallic ions experimented, Ag offers the highest potential with well documented antimicrobial properties even for superbugs such as methicillin-resistant Staphylococcus aureus (MRSA) [42].

Electrodeposition and anodising have also used to introduce Ag ions in implants, which has also shown infection resistance without altering biocompatibility [41]. In particular studies [43] have shown that anodised surfaces with consistent Ag release can even destroy mature bacterial biofilms. Studies $[25,44]$ also show that the antimicrobial performance of silver and be coupled 
with antibiotics to further enhance the membrane permeability of $\mathrm{Ag}$ ions; an ability that is particularly advantageous in combating antimicrobial-resistant (AMR) bugs. Direct AM of pure $\mathrm{Ag}$ was thus worth investigating as it allows for further incorporation of the best strategy to combine different methods to develop infection resistant implants.

Despite the established use of Ag nanoparticles [45-47], ions [48-50], alloys [51-54], and coatings [55-57], no studies have reported AM of pure silver. This means that little is known regarding the mechanical behaviour of pure silver from an additive manufacturing perspective. While AM pure Ag by itself might not offer the required structural strength for replacing cortical bone, it can lend itself to the development of hybrid implants that offer antibacterial efficacy without secondary post-processing. This not only reduces the cost of developing fully porous antibacterial bone scaffolds but also accelerates the bench to bedside development of patient-specific antibacterial scaffolds. Furthermore, AM pure Ag scaffolds can be used as a cancellous bone replacement as they may offer comparable strength [58]. Furthermore, direct AM of pure Ag will serve as the basis for the development of new functional Ag-based biomaterial and alloys suitable for infection resistant total bone replacement.

When it comes to the manufacturing process, research $[28,59]$ suggest that the infection resistance of Ag-coated implants were influenced by the fabrication process due to its effect on the ion release. While soaking AM Ti implants surface with Ag showed antimicrobial properties, chitosan assisted $\mathrm{Ag}+$ showed no efficacy towards Staphylococcus aureus (S. aureus) infection. Resistance to S. aureus is critical as a significant proportion of all scaffold infections are caused by the S. aureus species. Accordingly, this study not only pioneers the development of additively manufactured pure silver but also establishes its mechanical property and antibacterial efficacy towards S. aureus; the most common implant infection-causing microbe.

Numerous biomaterials such as CoCr and Ti alloys show excellent mechanical properties such as strength, toughness, corrosion, and wear performance [60,61]. However, these materials are not inherently antibacterial and various surface techniques are often sought for inducing antimicrobial properties. In most cases, the antimicrobial agents used are metal particles such as silver $(\mathrm{Ag})$, copper $(\mathrm{Cu})$, gold $(\mathrm{Au})$, and zinc $(\mathrm{Zn})$. Among these, $\mathrm{Ag}$ or $\mathrm{Ag}$ ions $(\mathrm{Ag}+)$ have long been reported to have excellent antibacterial activity [62]. The most recent study carried out by Liang et al. [63] suggests that surface modification of CoCr alloy by silver coatings is generally considered the most efficient way to reduce the bacteria and microbial adhesion. The scope of this study is limited to the performance of additively manufactured pure silver, which is structurally weak in comparison to $\mathrm{CoCr}$ or $\mathrm{Ti}$, however, the advantage is its antimicrobial property. The intention of developing AM pure Ag is not to be used as a standalone material to compete with existing biomaterials. Now that the parameters and performance of laser melted pure Ag is understood, effective alloys can be developed that delivers a good balance between mechanical and antimicrobial property. 
The investigations on the biocompatibility of metallic Ag, their micro-particulates, and implant devices are still in their infancy. Comprehensive studies are required to fully understand the biocompatibility associated with Ag metal particulate exposure in general. In vitro studies shows that a time and dose-dependent impairment of cell viability and cell proliferation of bone-forming cells exists after AgNp incubation. Pauksch et al. [69] confirm that the cytotoxicity of the AgNP occurred at higher concentrations, which can be reduced by incorporating AgNP into other biomaterials or using micron particulates. This aspect was demonstrated in studies conducted by Kanwal et al. [70] where the in vitro biocompatibility of the Ag at varying concentration was verified by the MTT assay. The results showed all concentrations to be non-toxic up to $10 \mu \mathrm{g}$ ml-1 with cell viability values of more than $70 \%$. However, at higher concentrations (up to 20 ug ml-1), samples became moderately toxic. A similar trend of increasing cytotoxicity against human cell line U937 by increasing particle concentration was reported by Nyga et al. [71]. However, it is important to remember that all these tests were carried out in vitro using AgNPs.

One of the most extensive studies on bulk Ag coated medical devices were carried out by Jansen et al. [72] where animal studies showed no signs of acute toxicity or adverse tissue reactions during an observation period of 3 days. Long term implantation data from rabbit paravertebral muscle for periods of 3,10 , and 30 days also showed no significant differences between Ag coated and uncoated samples [73]. Overall, Ag coated samples did not reveal differences in biological reactions compared to the control in short term toxicity tests as well as in implantation studies. These biocompatibility data were also consistent with studies reported by Spadaro et al. [74] on mouse bone marrow cells treated with pure Ag. Other relevant works include Chu et al. [75], who investigated silver-treated nylon sutures that revealed excellent biocompatibility. Overall, in vivo analysis using bulk silver coating shows that silver is biocompatible at a low dosage with no adverse local tissue responses.

Even though the data on the influence of $\mathrm{Ag}$ on bone regeneration is limited, Zhang et al. [76] report that Ag particulates have favourable osteogenic properties. Osteogenesis in general is a complex process. In most cases, it follows the formation of cartilage by chondrocytes, which is then removed and replaced by bone by osteoblasts. Osteoblasts develop from mesenchymal stem cells (MSCs) found in the periosteum and the bone marrow. MSCs differentiate through preosteoblasts, transited osteoblasts, and finally into mature osteoblasts. Pre-osteoblasts and transited osteoblasts are mitotically active, expressing alkaline phosphatase, but do not secrete bone matrix. Mature osteoblasts are mitotically inactive but are capable of secretion of the bone matrix that contains the relevant proteins and minerals. The bone matrix protein is mainly collagen, which provides tensile strength. The matrix is then mineralised by the deposition of a calcium-phosphate-hydroxide that provides compressive strength. Ag particulates exhibit new and unusual biological properties on cells in that they increase the rate of wound closure by promoting the proliferation and migration of keratinocyte on one hand, while driving the 
differentiation of fibroblasts into myofibroblasts, on the other hand, thereby promoting wound contraction [77-79].

As demonstrated in previous studies [64-68] AM as a process is now a proven and efficient method in fabricating custom geometry with targeted properties including patient-specific bone scaffolds. Nevertheless, further improvements in both materials and processes are still necessary before its clinical adoption to achieve both infection resistance and biomechanical performance. Accordingly, this research investigates the development of additively manufactured $99.9 \%$ pure silver bone scaffolds for the first time. The study reports the necessary process parameters to print $97 \%$ dense pure Ag using selective laser melting (SLM) technique. The mechanical performance of the printed $\mathrm{Ag}$ was then systematically studied and its antibacterial efficacy towards Staphylococcus aureus (S. aureus) evaluated. The established process parameters were then used to conceived two fully porous bone scaffolds at approximately $68 \%(w t$.) and $90 \%$ porosity, and their performance validated using both analytical and experimental techniques. Emerging visualisation techniques such as X-ray nanotomography (X-ray $\mathrm{nCT}$ ) was to use to analyse the overall quality of pure-Ag scaffolds and to identify potential internal defects. This is the first study on the SLM of pure-Ag antibacterial bone scaffolds and it is anticipated to accelerate the bench to bedside development of infection resistant Ag-based hybrid scaffolds that do not require significant post-processing treatments or coating.

\section{Methodology}

\subsection{Additive manufacturing and materials}

All experimental samples were additively manufactured using gas atomised 99.9\% pure-Ag with morphology as shown in Fig. 1a. It can be seen that the powdered particles are spherical and have satellite particles attached. The average size (dia.) of the satellite particles was found to be $2 \mu \mathrm{m}$. Particle size analysis was carried and identified that the size distribution was between 18.8-38.6 $\mathrm{mm}$. The particle volume distribution (PVD) was relatively evenly spread with only $10 \%$ of particles below $18.8 \mu \mathrm{m}$ that can be primarily distinguished as smaller satellite particles. This meant that the atomised Ag powder used in this study featured a near-normal size distribution, which is favourable for SLM.

The composition of the powdered post-atomising was evaluated using energy dispersive spectroscopy (EDS), the result of which are presented in Fig. 1b. The EDS analysis was critical to analyse the purity of the feedstock as contaminants can cause significant variation in the thermomechanical behaviour during laser melting. The EDS analysis confirms that the powder was $100 \%$ pure with no contaminants and oxidation.

A Powder Bed Fusion (PBF) machine featuring a $400 \mathrm{~W}$ fibre laser system was used for SLM.

A $370 \mathrm{~W}$ overhead laser system was precisely modulated based on the process parameters to generate the pure-Ag melt pool. The scan speeds were varied from 400 to $1000 \mathrm{~mm} / \mathrm{s}$ at $50 \mathrm{~mm} / \mathrm{s}$ 
increments. This range was selected to maximise the energy input while allowing for a realistic fabrication speed. While the lower scan speed $(400 \mathrm{~mm} / \mathrm{s})$ allows for a high energy density input to produce single tracks; higher scan speeds are desirable as they reduce build time making the process more cost-effective. Standard materials in comparison such as Aluminium (Al) and Titanium (Ti) have scan speeds of 800 and $1250 \mathrm{~mm} / \mathrm{s}$ respectively.

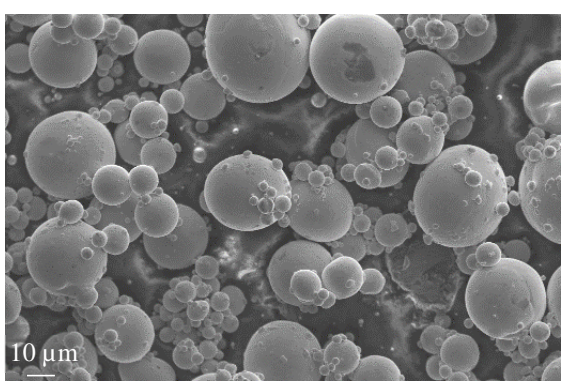

(a)

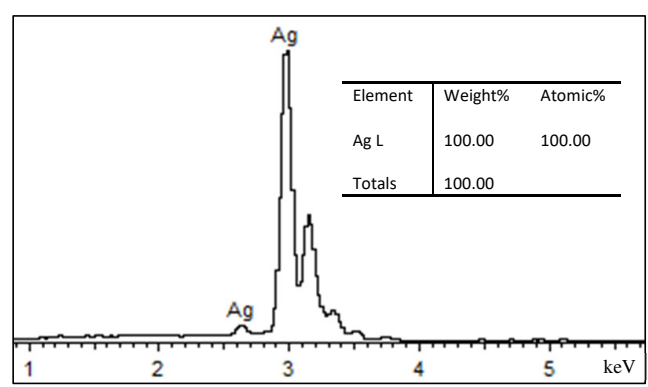

(b)

Fig. 1. SEM and EDS data showing (a) atomised pure-Ag particles used for SLM and (b) corresponding elemental analysis to assess contamination.

Measurements were taken along each molten track produced and the maximum, minimum, average, and range were recorded for the bead width. All tests were conducted in an argon atmosphere with oxygen content in the process chamber below $0.1 \%$. The laser melting process was carried out on substrates that were heated to $35^{\circ} \mathrm{C}$. Finally, the process parameter combination that achieved the highest density (97\%) was chosen to fabricate the experimental specimens as listed in Table 1. These parameters were selected as they were found to be optimum for the size of the smallest wall thickness $(0.3 \mathrm{~mm})$ being manufactured and resulted in a $97 \%$ dense part.

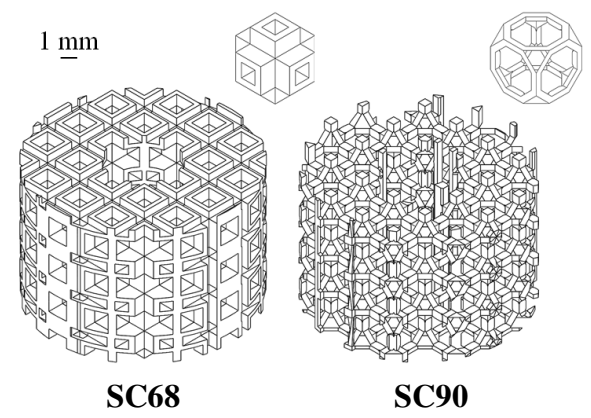

Fig. 2. The scaffold designs and the associated unit cells where SC68 and SC90 feature a porosity of 68.46 and $90.69 \%$ (vol.) respectively. The scaffolds have a height of $10 \mathrm{~mm}$ and a diameter of $14.5 \mathrm{~mm}$.

The CAD data for scaffold fabrication was advised by a previous study [64] and featured a low and high porosity design namely SC68 and SC90 as shown in Fig. 2. The two designs were chosen to conceive a relatively simple and complex bone scaffold while meeting all the porosity requirements associated with bone ingrowth. Due to the porous nature of the scaffolds, a diagonal self-supporting build was carried out without the use of internal support structures. Following the SLM process, submerged wire Electro-Discharge Machining (EDM) was employed to remove the as-built samples for further analysis. 


\subsection{Morphological analysis}

\subsubsection{X-ray nanotomography}

The overall porosity and defect analysis of the SLM samples were carried out using multiscale $\mathrm{X}$-ray nanotomography (X-ray $\mathrm{nCT})$. X-ray $\mathrm{nCT}$ is a rapidly emerging non-destructive analysis tool suitable to study the structural integrity and internal details in a wide range of materials [80]. The non-destructive nature of the technique allows the analysis of internal defects and pores of the same components that can later be subjected to conventional experimental testing. The technique is increasingly being used in AM due to the synergy between the complexity of SLM and porosity defects.

The system used in this study was the Skyscan 2211 multiscale X-ray nCT manufactured by Bruker. The SLM samples were mounted on a rotary platform suspended on air bearings and placed between the X-ray source and the receiver. Each sample was then rotated $360^{\circ}$ at $0.1^{\circ}$ incremental points. For each sample, approximately 11000 images were collected. A Gaussian smoothening at a kernel size range between 0.5 and 0.7 was used for the reconstruction.

A region of interest (ROI) method using CTVox (Bruker) was applied to the reconstructed data and the volumetric porosity was evaluated using the inverse data method. To do this, a watershed segmentation of the raw data was carried out to obtain a binary histogram where different phases were assigned to voxels corresponding to pores and material. The scan data was visualised using a 3D volume rendering and iso-surface module. Although the technique is emerging, the method results in highly accurate porosity evaluation and widely considered best practice [80]. The individual X-ray scans took $\sim 4 \mathrm{hrs}$ and each reconstruction $\sim 3 \mathrm{hrs}$ using a 40 core xeon workstation expending 128 GB of RAM supported by CUDA enabled GPU acceleration.

\subsubsection{Surface characterisation and elemental analysis}

The 2D surface data of the SLM samples were evaluated using a Zeiss scanning electron microscopy (SEM). The surface roughness of the implant resulting from DMLS was evaluated using an Olympus LEXT OLS3100 confocal laser scanning microscope. The laser identified the lowest site and referenced this as zero, from which peaks and valleys were referenced to evaluate the mean surface roughness value. Energy dispersive spectroscopy (EDS) was used to carry out the elemental analysis to assess the purity of both the pure Ag feedstock and printed samples. For the pure Ag powder (Fig. 1), the EDS analysis was used to determine the elemental composition of individual points. A total of three points were analysed. To analyse the scaffold sample (Fig. 13) contamination inclusive of the surrounding base metal (Ag), finite area scans were collected for a spectrum of the lateral distribution of elements from the imaged area.

Page 7 of 32 


\subsection{Mechanical testing}

Both tensile and compressive tests to evaluate the material performance of SLM Ag and the performance of porous scaffolds were carried out using a Zwick Roell Z1474 universal materials test rig (Fig. 3) having a maximum load capacity of $100 \mathrm{kN}$. The tests were carried out to obtain the stress-strain $(\sigma-\varepsilon)$ responses for all the specimens. Before commencing the tests the rig was calibrated and verified following BSENISO 7500-1 [81]. While the tensile coupons were pulled to failure the scaffolds were compressed to a maximum deformation of $60 \%$ at $0.01 \mathrm{~mm} / \mathrm{s}$.

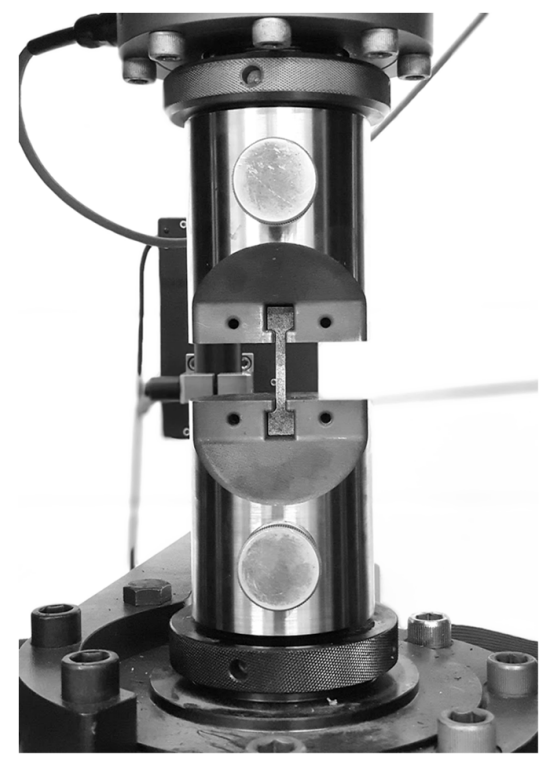

Fig. 3. Experimental test rig used for the mechanical testing of Ag samples.

In all cases, a crosshead-controlled displacement with an $80 \mathrm{kN}$ threshold was used to keep the compression from stopping at the yield limit. Deformation beyond the elastic limit was essential to study the failure modes and the overall behaviour of both the pure-Ag material and scaffolds. Based on the $\sigma-\varepsilon$ curve, the properties of the test samples were characterised for Young's modulus $(\mathrm{E})$, elastic limit $\left(\sigma_{e}\right)$, yield strength $\left(\sigma_{y}\right)$, ultimate strength $\left(\sigma_{u l t}\right)$ and ultimate strain $\left(\varepsilon_{u l t}\right)$. To ensure data quality, all the mechanical testing was carried out using non-slip platens whose performance was monitored through a Nikon high definition video capturing device. The device was calibrated, and the captured frame-by-frame data of the sample and strain locations were then analysed to make sure the recorded strain is accurate. The relative motion of both the sample and crosshead was also monitored to identify any sample slippage for both the compressive and tensile test cases. Two samples were tested for each category under identical conditions to ensure the consistency of data observed.

\subsection{Antimicrobial evaluation}

The antimicrobial properties of the SLM pure-Ag were evaluated in vitro against Staphylococcus 
aureus (ATCC 6538) obtained from the American Type Culture Collection (LGC Standards, Teddington, UK). S. aureus was chosen for the initial analysis as they cause two-thirds of all orthopaedic implant infections and they are the principal causative agents of infection affecting bone [3]. The organism was cultured for 24hrs on tryptone soy agar (Oxoid, Basingstoke, UK) at $32^{\circ} \mathrm{C}$ to allow for colony formation. After incubation, overnight suspensions of bacteria were prepared in Dulbecco's Phosphate Buffered Saline (DPBS) solution at a concentration of $1 \times 10^{7}$ to $1 \times 10^{8} \mathrm{CFU} / \mathrm{ml}$. SLM pure-Ag disk was disinfected for $20 \mathrm{~min}$ in $70 \%$ propan-2-ol followed by air drying. Each disk was placed into 12 well plates containing $1 \mathrm{~mL}$ DBPS per well one disk was placed per well and inoculated with $0.01 \mathrm{ml}$ of the overnight suspension. The plates were then incubated at $30^{\circ} \mathrm{C}$ and $70 \mathrm{rpm}$. At predetermined time intervals samples were taken, serially diluted, and plated on agar plates using WASP Touch Spiral Plater (Don Whitley, Bingley, UK) and incubated at $32^{\circ} \mathrm{C}$ for $24 \mathrm{~h}$. The resulting colonies were counted using an aCOLyte $3 \mathrm{HD}$ automated colony counter (Synbiosis, Cambridge, UK), and the reduction in viable bacterial cells was plotted as the log reduction in viability for each time point compared to zero-time viability. DPBS solution was used as a negative control. The methodology is widely used to characterise antibacterial performance when it comes to biomaterials [82].

\section{Results and discussion}

\subsection{Additively manufactured pure silver}

\subsubsection{Mechanical performance and process parameters}

Although materials such as aluminium, gold, and copper have been proven to be suitable for the SLM process, little is known regarding the AM of pure silver, let alone their mechanical

performance. In this regard, before demonstrating the AM pure-Ag porous bone scaffolds, it was critical to understand the mechanical performance of laser melted pure Ag material. This was critical as the result of the SLM parametric analysis depends on laser power $\left(P_{l}\right)$ layer thickness $\left(t_{l}\right)$, scan speed $\left(v_{s}\right)$ and hatch spacing $\left(h_{s}\right)$. Overall, the highest part density of $\sim 97 \%$ was achieved at three sets of parametric combinations as shown in Table 1.

Table 1. SLM process parameters used to additively manufacture pure silver tensile test coupons.

\begin{tabular}{cccccc}
\hline Part identifier & $(\mathrm{W})$ & $\boldsymbol{t}(\boldsymbol{\mu m})$ & $\boldsymbol{v}_{\boldsymbol{s}}(\mathbf{m m} / \mathbf{s})$ & $\boldsymbol{h}_{\boldsymbol{s}}(\mathbf{m m})$ & $\boldsymbol{\rho}_{\boldsymbol{r}}$ \\
\hline 4T0.16 & & & 400 & 0.16 & \\
$4 \mathrm{~T} 0.20$ & 370 & 0.3 & 400 & 0.20 & $97 \%$ \\
$8 \mathrm{~T} 0.16$ & & & 800 & 0.16 & \\
\hline
\end{tabular}

To evaluate the feasibility of laser melting pure Ag and to identify optimum process parameters the atomised silver powder was laser processed on steel and copper substrates. The common practice for the selection of substrate materials was to use the same substrate as the processing material. However, this was not feasible for this study due to the high cost associated with pure silver. Accordingly, both copper and steel substrate were systematically evaluated and found 
steel to be the most suitable at $370 \mathrm{~W}$ without any miscibility. Consequently, a steel substrate was used to manufacture all the Ag samples used in this study.

The selection of the most suitable SLM process parameter to print the bone scaffold was to consider not only the part density but also the mechanical performance. Although numerous SLM parameters exist, the laser power, scanning speed, hatch spacing, and layer thickness are widely accepted [83-85] as the most common process parameters that can be adjusted to optimise the process. For pure silver, the tensile test specimens conceived at the three parametric combinations as shown in Table 1 generated a $\sim 97 \%$ dense material. The relative density observed for SLM pure silver can be seen to be at par with the highest ${ }_{r}$ recorded for some of the emerging and reflective materials as listed in Table 2. In particular, the pure-Ag process parameters presented in this study delivers a ${ }_{r}$ comparable to sterling silver and copper.

Table 2. Highest reported relative density for AM reflective materials compared to pure silver.

\begin{tabular}{lll}
\hline SLM material & $\boldsymbol{\rho}_{\boldsymbol{r}}(\boldsymbol{\%})$ & Ref. \\
\hline $\mathrm{Cu}$ & 97.00 & Colopi et al. $[86]$ \\
$\mathrm{W}$ & 89.92 & Deprez et al. $[87]$ \\
$\mathrm{Mg}$ & 82.00 & Zhang et al. $[88]$ \\
$\mathrm{Au}(24$ Carat) & 89.60 & Khan and Dickens [89] \\
Sterling Ag (purity $<92.5 \%)$ & 96.70 & Xiong et al. $[51]$ \\
Pure Ag & 97.00 & This work \\
\hline
\end{tabular}

In addition to ${ }_{r}$, the resulting mechanical performance was also used as a benchmark to select the best SLM process parameters to build the scaffold designs. This strategy was chosen as it allows to consider the process parameters that simultaneously deliver both the highest relative density and structural integrity. Having tested numerous specimens, the highest and lowest stress-strain $(\sigma-\varepsilon)$ curve observed for all of the process parametric combinations that delivered the highest (97\%) relative density are presented in Fig. 4. The respective failed samples are shown in Fig. 6.

Analysing the $\sigma-\varepsilon$ curves (Fig. 4a-c) reveals consistent elastic and plastic regions for all the tensile coupons tested. However, despite featuring the same ${ }_{r}(97 \%)$ for all the samples tested, a certain difference in the $\sigma-\varepsilon$ performance can be observed between each of the three process categories. The respective mechanical performance derived from each of the characteristic regions of the $\sigma-\varepsilon$ is summarised in Table 3. Overall, the highest Young's modulus of 17.8 GPa was exhibited by the Ag specimen manufactured at a scan speed and hatch distance of $800 \mathrm{~mm} / \mathrm{s}$ and $0.16 \mathrm{~mm}$ respectively. The Young's modulus of $8 \mathrm{~T} 0.16$ was closely followed by $4 \mathrm{~T} 0.16$ and 4T0.20 at 15.6 and $15.5 \mathrm{GPa}$ respectively.

From the $\sigma-\varepsilon$ data, it was clear that the hatch distance has a higher influence on the mechanical properties of dense pure Ag when SLM processed at $370 \mathrm{~W}$. Even though, 4T0.16 
and $4 \mathrm{~T} 0.20$ featured the same $v_{s}$, the difference in $h_{s}$ has contributed to the $\sim 0.6 \%$ change in Young's modulus between the specimens. Overall, the highest difference of $13.8 \%$ in E was observed between the best (8T0.16) and worst (4T0.20) performing case demonstrating the influence of $v_{S}$ despite the same ${ }_{r}$. Nevertheless, the difference in E was found to be negligible $(0.6 \%)$ between the two cases sharing the same scan speed $(400 \mathrm{~mm} / \mathrm{s})$. This shows that the scan speed has the highest influence on the stiffness of the dense pure silver manufactured using SLM.

A similar trend was observed when it comes to elastic limit, yield strength, ultimate strength, and ultimate strain, with 8T0.16 outperforming the other two cases. Out of all the mechanical properties evaluated, $\varepsilon_{u l t}$ showed the largest difference where $8 \mathrm{~T} 0.16$ outperformed $4 \mathrm{~T} 0.20$ by 42.3\% . This demonstrates the significance of scan speed and hatch spacing on both the toughness and ductility of the SLM processed pure silver. In all the cases, the failure of the samples was consistent (Fig. 6) confirming the repeatability and validity of the observations.

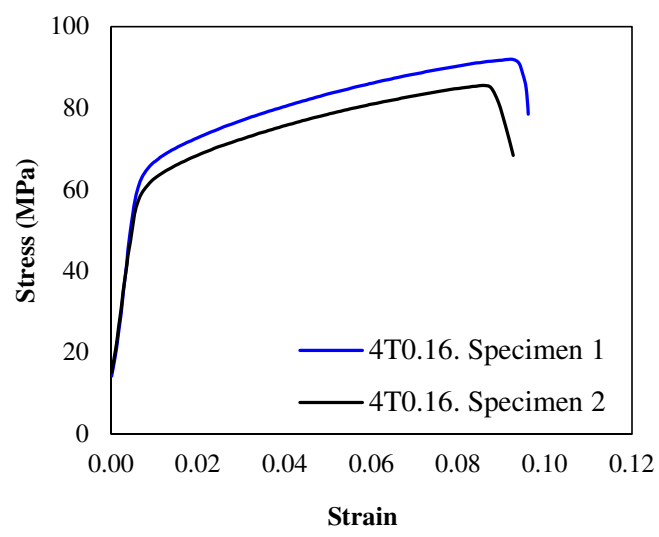

(a)

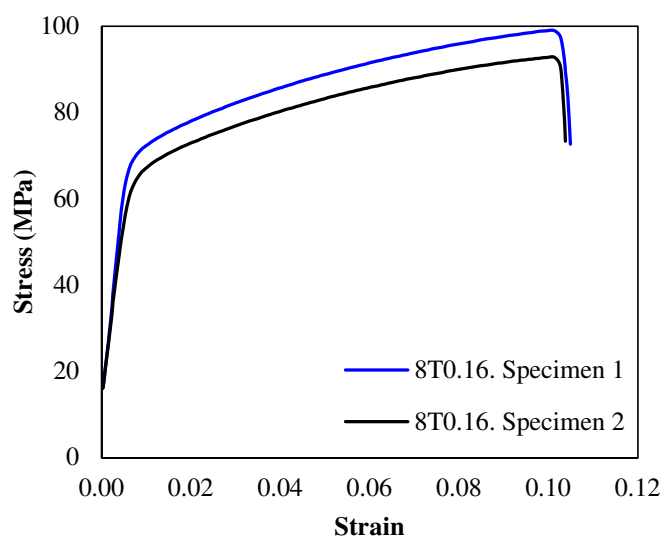

(c)

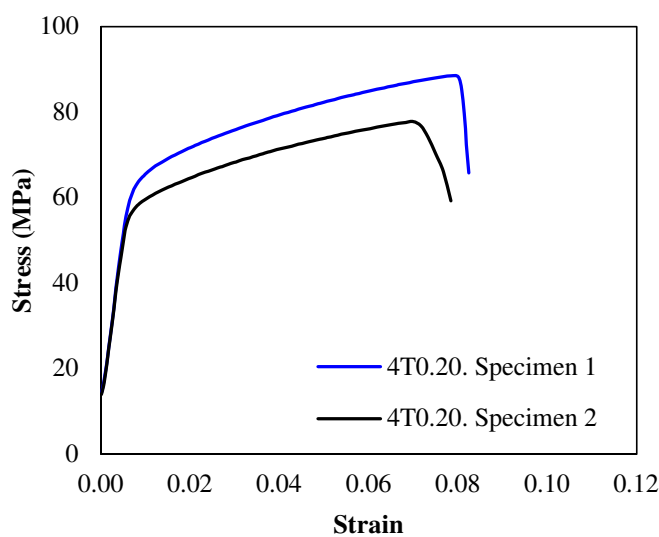

(b)

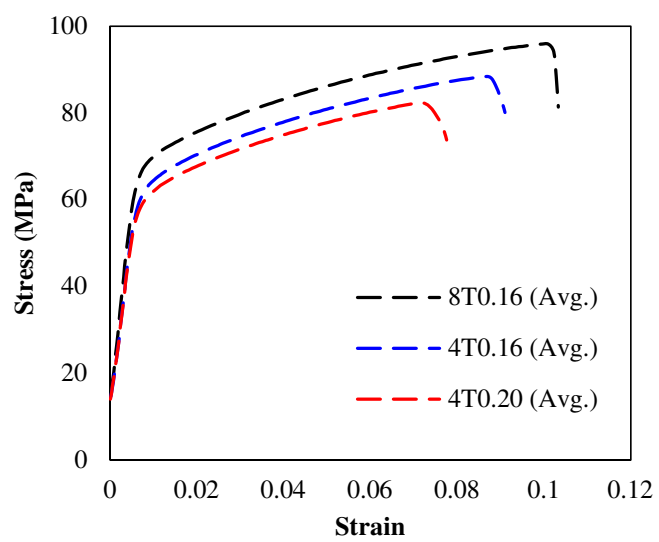

(d)

Fig. 4. Stress-strain curve for 97\% dense SLM pure-silver tensile coupons at different process parameters was (a), (b) and (c) shows the highest and lowest performance at the respective scan speed and hatch spacing; (d) compares the average performance between the three SLM process cases considered. 
To put these observations into perspective the cumulative parameter, 'laser energy density $\left(e_{l d}\right)$ ' has to be introduced [90-93]. It is widely considered as the critical parameter to characterise both the manufacturability [94] and mechanical performance [95] of SLM components and generally represents the energy density in $J / \mathrm{mm}^{3}$ as shown in Eqn. (1):

$$
e_{l d}=\frac{P_{l}}{v_{s} \times h_{s} \times t_{l}}
$$

where $P_{l}$ is the laser power (Watt), $t_{l}$ is the layer thickness $(\mathrm{mm}), v_{s}(\mathrm{~mm} / \mathrm{s})$ is the scan speed and $h_{s}(\mathrm{~mm})$ is the hatch distance. Despite keeping $P_{l}$ and $t_{l}$ constant, 8 T0.16 results in the lowest energy density of the three SLM process combinations considered. This subsequently affects the thermo-physical properties during laser melting and hence affects the mechanical properties of the manufactured parts.

Table 3. Mechanical performance of SLM manufactured $97 \%$ dense pure silver, where E, $\sigma_{e}, \sigma_{y}, \sigma_{u l t}$ and $\varepsilon_{u l t}$ are the Young's modulus, elastic limit, yield strength, ultimate strength, and ultimate strain respectively.

\begin{tabular}{cccccc}
\hline Identifier & $\mathrm{E}(\mathrm{GPa})$ & $\boldsymbol{\sigma}_{\boldsymbol{e}}(\mathrm{MPa})$ & $\boldsymbol{\sigma}_{\boldsymbol{y}}(\mathrm{MPa})$ & $\boldsymbol{\sigma}_{\boldsymbol{u l}}(\mathrm{MPa})$ & $\varepsilon_{\boldsymbol{u l}}$ \\
\hline $4 \mathrm{~T} 0.16$ & $15.6 \pm 0.2$ & $52.63 \pm 1.48$ & $61.68 \pm 1.76$ & $88.42 \pm 2.84$ & $0.085 \pm 0.0046$ \\
$4 \mathrm{~T} 0.20$ & $15.5 \pm 0.4$ & $50.71 \pm 2.38$ & $57.56 \pm 1.94$ & $82.43 \pm 2.74$ & $0.071 \pm 0.0035$ \\
$8 \mathrm{~T} 0.16$ & $17.8 \pm 0.4$ & $57.74 \pm 1.59$ & $67.15 \pm 1.61$ & $95.92 \pm 2.53$ & $0.101 \pm 0.0002$ \\
\hline
\end{tabular}

According to Munir and Wen [96], the energy density at the powder bed during SLM primarily governs the microstructure and properties of as-built parts, which subsequently relate to the resulting mechanical performance. This energy density can be measured as the average applied energy from the laser per volume of material during the scanning of an individual layer. $h_{s}$ is a measure of the separation between two consecutive laser tracks: centre-to-centre distance from one to the next laser scan (Fig. 5a). Scan spacing is directly proportional to the production speed. If it is high, it will take less time for the laser to scan the layer, if low, additional scans were required to execute the whole layer. Even though, an $h_{s}$ of 0.16 and $0.20 \mathrm{~mm}$ in this instance delivered a $\sim 97 \%$ part, the density at the higher $h_{s}$ of 0.20 may have been composed of partly melted or sintered powder, which explains the lower mechanical performance. While at this stage it was merely a hypothesis, $\mathrm{X}$-ray $\mathrm{nCT}$ analysis was consulted in later sections of this paper to further explore this aspect.

During the heating and melting of pure silver, consideration should also be given to heat capacity and latent heat [97]. These are heavily dependent on the material and proportional to the mass being melted. Accordingly, insufficient energy as a result of high $v_{s}(>800 \mathrm{~mm} / \mathrm{s})$ leads to balling due to lack of wetting of molten pool with the preceding layer; low $v_{s}(<800 \mathrm{~mm} / \mathrm{s})$ results in extensive material evaporation and the keyhole effect. In any case, un-optimal $h_{s}$ leads to regular porosity as a result of insufficient melt overlap preventing the material layers from fusing as 
shown in Fig. 5b. This was why despite the three parametric combinations resulting in similar relative density the mechanical performances were different.

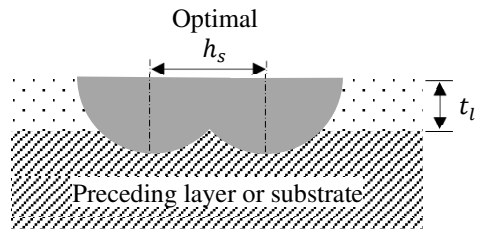

(a)

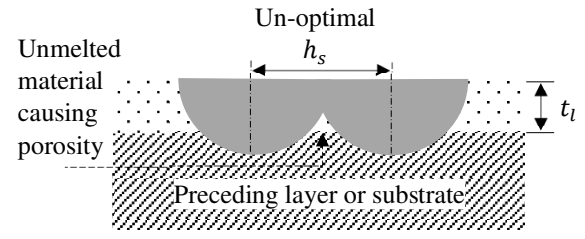

(b)

Fig. 5. The creation of regular porosity throughout the structure as a result of un-optimal hatch spacing $\left(h_{s}\right)$, where (a) shows two adjacent SLM material beads using an optimal $h_{s}$ and (b) trapped unmelted material causing porosity as a result of un-optimal $h_{s}$.

Vaporisation [98] as a result of high $e_{l d}$ during melting was another aspect which affects the performance. This leads to condensation of volatilised materials resulting in fewer but large pores, which explains the lower performance of 4T0.16. Hence, a suitable combination of $P_{l}, v_{s}$, $h_{s}$, and $t_{l}$ is essential to manufacture repeatable and high-quality SLM parts. Accordingly, for pure silver, the SLM process parameters associated with 8T0.16 summarised in Table 1 delivers the best performing dense parts. As a result, this combination of SLM process parameters was chosen to manufacture the scaffold prototypes considered in this study. Nevertheless, to fully explain the reasons for the difference in mechanical performance despite similar ${ }_{r}$, a fracture surface analysis and defect characterisation were carried out.

\subsubsection{Fracture and defect characterisation}

Analysing the $\sigma-\varepsilon$ curve (Fig. 4) for as-built Ag in conjunction with the failed samples (Fig. 6) further; it was clear that the strain associated with failure was representative of a semi-ductile metallic material. A semi-ductile classification was most appropriate as the performance and associated failure of the SLM pure Ag exceeds a $5 \%$ strain at fracture $\left(\varepsilon_{u l t}\right)$ but falls close to or below $10 \%$ at failure. The reason for moderate ductile behaviour can be identified from the SEM fractography of the failed samples which reveals a semi-ductile fracture as shown in Fig. 7.

This is different from the pure ductile performance usually exhibited by traditionally manufactured silver. As it can be seen, an appreciable amount of permanent plastic deformation accompanies the fracture that was largely manifested macroscopically across the cross-section in the form of distortion or micro-necking. The normal practice is to test at least five tensile samples of a material to ensure a consistent stress-strain curve. However, for the case under consideration, only two samples of each variant of the tensile specimen were tested. This was primarily because of the high cost associated with pure silver. Therefore, it is crucial to evaluate the failed samples to see whether the failure is consistent. Overall, the failure mode can be seen to be consistent as shown in Fig. 6. 


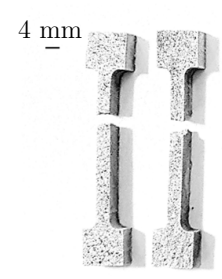

4T0.16

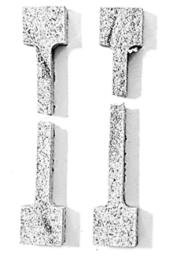

4T0.20

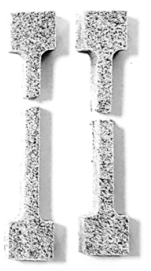

8T0.16

Fig. 6. Failed $97 \%$ dense pure-silver tensile-test coupons under different SLM process parameters.

The cross-section of the fracture surface shows a specific pattern where dimples of various size, shape, and distribution can be observed (Fig. 7). Failure was dominated by the growth of coarse voids between dimpled peaks consecutively being strained to failure. This can be seen to create lower size secondary dimples showing an assigned distribution of pores which have consistently grown during plastic deformation. The existence of un-melted or partially sintered Ag particles at the fractured surface explains the lower mechanical performance despite a $97 \%$ density. Despite the elongated peaks characteristic of a ductile behaviour, brittle 'river markings' [99] can also be observed in Fig. 7 explaining the comparatively low $\varepsilon_{u l t}$. For a traditional classification of brittle failure based on $\sigma-\varepsilon$ curve, a plastic strain less than $5 \%$ is called for by Callister and Rethwisch [100]. Consequently, a semi-ductile failure is the most appropriate classification for $97 \%$ dense laser melted $99.9 \% \mathrm{Ag}$.

To further understand the reason for the semi-ductile behaviour a representative section of the tensile specimen was scanned using the $\mathrm{X}$-ray nCT as shown in Fig. 8. The use of X-ray nCT for the non-destructive measurement of density and porosity defects and distribution is an emerging practice that applies particularly well to AM parts. According to Li and Fu [101], semiductile fracture of metallic materials is influenced by numerous factors including material state, workpiece geometry, and strain path. Under tension, semi-ductile fracture starts as a result of nucleation growth, and coalescence of micro-voids. Accordingly, looking at the X-ray nCT data of the SLM pure Ag dense samples as shown in Fig. 8, a certain distribution of micro-voids was visible. This not only explains the rapid reduction in mechanical performance but also observed fractography leading to semi-ductile behaviour.

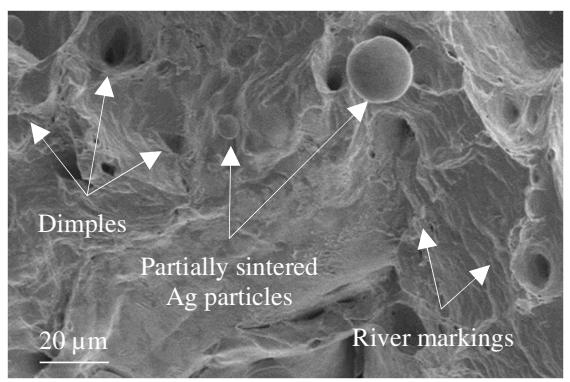

Fig. 7. SEM fractography of the failed tensile sample surface. 
Overall, it can be confirmed that the fracture mechanism involves the linkup of voids from multiple planes. Accordingly, the semi-ductile fracture occurs as a mixture of tension- and porosity induced damage. This explains the semi-ductile behaviour where the early nucleation was initiated as a result of crack propagation initiated by the voids representative of the ones shown in Fig. 8. The propagation of large nucleation cracks requires much less energy than pureductile crack and can occur at applied stress much lower than that at which failure would normally be expected. In other words, a high localised stress concentration facilitated by the preexisting micro-voids was the reason for the observed semi-ductile behaviour and the associated mechanical performance.

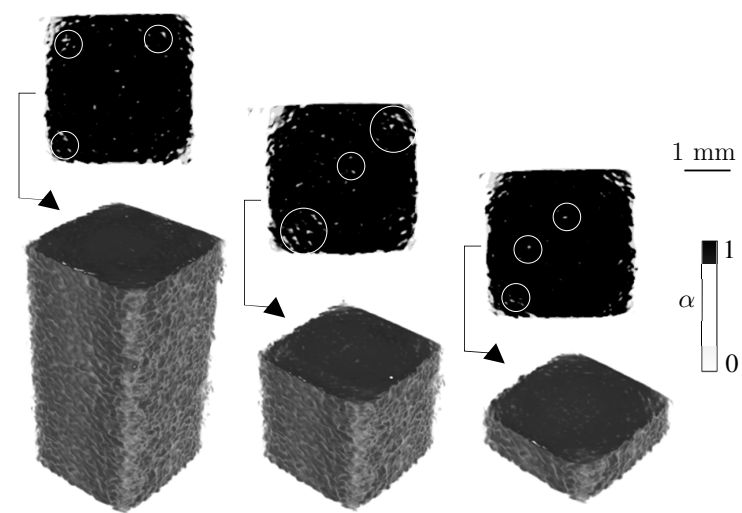

Fig. 8. Reconstructed X-ray nCT showing selected cross-sections of dense SLM pure silver prints with pores highlighted.

Even though this is the first study on the additive manufacturing of pure $\mathrm{Ag}$, the mechanical performance outperforms the performance of low temperature sintered silver carried out by Bai et al. [102]. While Bai reported an E and $\sigma_{y}$ of $10 \mathrm{GPa}$ and $43 \mathrm{MPa}$ respectively, the SLM process carried out in this study resulted in an E and $\sigma_{y}$ of $17.8 \mathrm{GPa}$ and $67.15 \mathrm{MPa}$ respectively, which accounts for an improvement of $56 \%$ and $43 \%$ for Young's modulus and yield strength respectively. Overall, it is clear that the mechanical performance of AM pure Ag is largely dependent on the SLM process parameters and the resulting part quality. For $99.9 \%$ pure Ag, the parameters associated with 8T0.16, summarised in Table 1 delivers the best performance and hence used to manufacture the scaffold prototypes considered in this study. Having sufficiently characterised the dense material, the manufacturability and performance of what can be considered as the first-ever AM pure silver bone scaffolds are brought forward in the subsequent sections.

\subsection{Additively manufactured pure silver porous bone scaffold}

\subsubsection{Selective laser melting}

To assess the suitability of additively manufacturing geometrically porous pure Ag bone scaffolds, two designs were conceived in this study. A low and high porosity cellular structure at 
$68.5 \%$ (wt.) and $90.7 \%$ respectively; the two versions were conceived to emulate a thick and thin strut thickness representative of porous structures suitable for bone ingrowth informed by previous studies [64]. The additively manufactured scaffolds prototypes using optimal process parameters (8T0.16) in pure Ag are shown in Fig. 9.

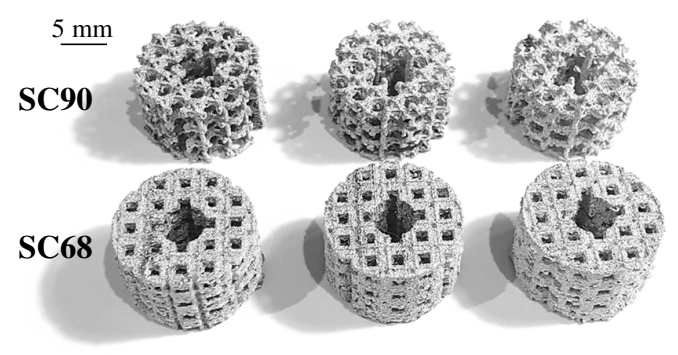

Fig. 9. As build AM pure Ag bone scaffold where SC90 and SC68 feature a porosity $90.7 \%$ and $68.5 \%$ respectively.

A rough surface finish as a result of characteristic stair-step effect during SLM was observed. The resulting morphology of as build $\mathrm{Ag}$ scaffolds is as shown in Fig. 10. While the interconnected porosity and the representative geometry closely followed the CAD (ideal geometry), the average strut thickness of SC90 was found to vary by approximately $50 \mu \mathrm{m}$. While this is in line with existing literature [103-106] on SLM of thin struts $(<300 \mu \mathrm{m})$, the comparatively low mechanical performance of silver means that the effects can be significant.

It can be seen from Fig. 10 that despite the existence of semi-molten particles on the surface, SC60 features significantly low thickness variations in comparison to SC90. This clearly shows that even though SLM has clear advantages fabricating complex shapes, there are still challenges when it comes to thickness closer to or less than $300 \mu \mathrm{m}$. Consequently the rational design of pure Ag scaffolds requires aspects of the SLM process to be considered. Even though, this was a case explored by some researchers [104,107,108], most porous models do not consider manufacturing artefacts nor implement the manufacturing limitations at the design stage. Studies carried out by Zadpoor [109] also shows this to be a critical aspect if ignored can significantly worsen the mechanical performance of additively manufactured porous structures.

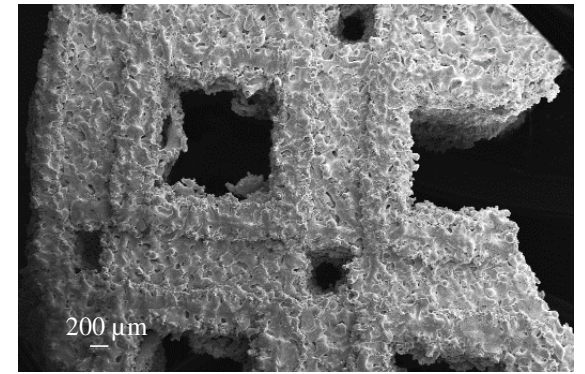

(a)

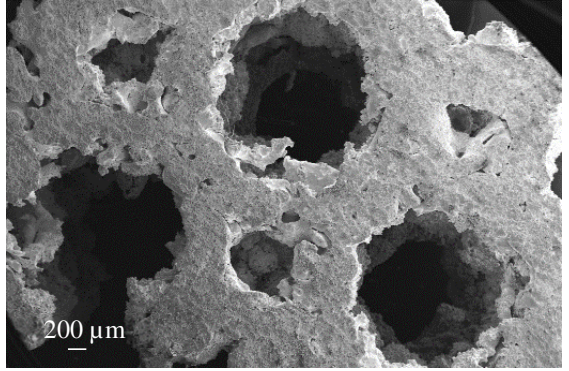

(b)

Fig. 10. Morphology of the as printed pure Ag scaffolds using SLM where (a) shows SC68 and (b) SC90. 


\subsubsection{Mechanical performance of Ag bone scaffold}

Before the experimental evaluation of the mechanical properties, Ashby's criterion $[65,66,110]$ for porous structures was used to characterise the relative mechanical performance of the scaffolds. The material properties (Table 3) of SLM Ag at a scan speed and hatch distance of $800 \mathrm{~mm} / \mathrm{s}$ and $0.16 \mathrm{~mm}$ was used as the bulk Ag properties for Ashby's model. The scarcity of literature on the mechanical performance of SLM Ag means that the relative characterisation was crucial in assessing the influence of the AM process on the resulting mechanical performance of the scaffolds. Porous structures can be divided into either stretch or bend dominated depending on their bending/stretching of the cell struts. Similar to a honeycomb structure, both SC90 and SC68 were bend-dominated. The subsequent evaluation under this criterial using Ashby's model results in the theoretical mechanical performance of the scaffold as listed in Table 4.

Table 4. Relative and experimentally measured mechanically performance of SLM pure Ag bone scaffolds.

\begin{tabular}{ccccccc}
\hline Scaffold & $\boldsymbol{\rho}_{\boldsymbol{r} \boldsymbol{d}}$ & $\boldsymbol{\varphi}(\boldsymbol{\%})$ & $\boldsymbol{\sigma}_{\boldsymbol{r}}(\mathrm{MPa})$ & $\boldsymbol{\sigma}_{\boldsymbol{y}(\boldsymbol{e x p})}(\mathrm{MPa})$ & $\boldsymbol{E}_{\boldsymbol{r}}(\mathrm{GPa})$ & $\boldsymbol{E}_{\boldsymbol{e x \boldsymbol { p }}}(\mathrm{GPa})$ \\
\hline SC68 & 0.32 & 68.46 & 37.71 & $44.58 \pm 5.2$ & 1.77 & $1.86 \pm 0.08$ \\
SC90 & 0.09 & 90.69 & 20.49 & $10.16 \pm 0.8$ & 0.15 & $0.13 \pm 0.02$ \\
\hline
\end{tabular}

According to Ashby's criterion, porosity $(\varphi)$ has an inverse relationship with both relative density, elastic modulus, and strength. SC68 exhibited a relative modulus and strength of 1.77 $\mathrm{GPa}$ and $11.89 \mathrm{MPa}$ respectively at a relative density of 0.32 . When the relative density changed to 0.09 , a ten-fold reduction in strength was observed resulting in $1.91 \mathrm{MPa}$ in comparison to SC68. When it comes to the relative elastic modulus, a 90\% reduction was observed between SC68 and SC90. This means that a high porosity structure using pure Ag may not be suitable for load-bearing applications unless suitable alloying elements can enhance the structural integrity. Nevertheless, the yield strength and elastic modulus were in the range of human cancellous bone suitable for reducing the effects of maladapted stress concentration and stress shielding according to Helsen and Missirlis [111]. Although the elastic modulus of porous pure $\mathrm{Ag}$ scaffolds presented here is below the stiffness of most human cortical bone [112].

Now that the theoretical performances are established for the scaffolds, the experimental $\sigma-\varepsilon$ performance for SLM pure Ag scaffolds are shown in Fig. 11 with the corresponding performance parameters summarised in Table 4. Generally, the stress-strain curve for cellular metallic materials represents three characteristic regions representing both the elastic and plastic performance. The first characteristic regions show both the linear and non-linear elastic deformation, where the $\sigma-\varepsilon$ proportionality is followed by a non-linear region ending in a stress peak commonly referred to as the ultimate strength $\left(\sigma_{u l t}\right)$. However, due to the considerable ductile behaviour of $\mathrm{Ag}$, neither $\sigma_{u l t}$ or $\varepsilon_{u l t}$ could be registered. A case similar to what was observed by Wauthle et al. while studying AM porous tantalum implants [58]. In both cases, 
the reason for this was the ductile behaviour of the material influencing what is otherwise a clear distinction between elastic and plastic performance.

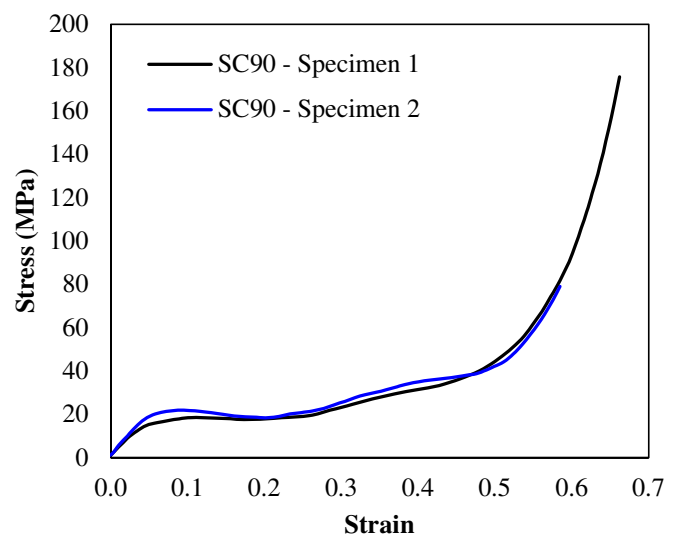

(a)

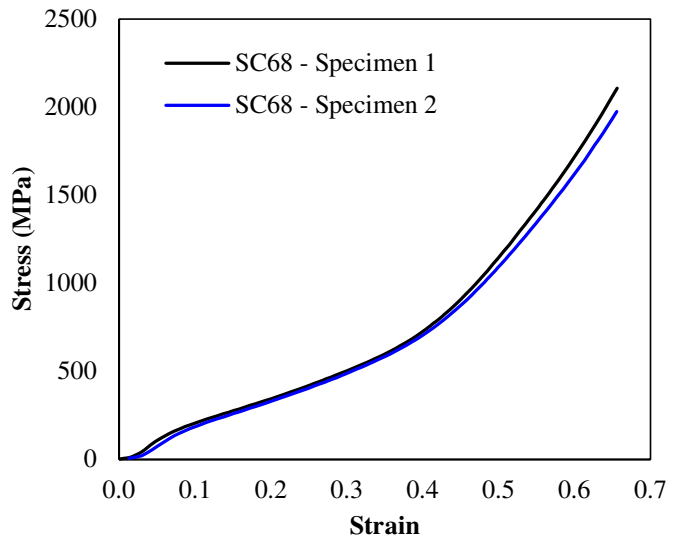

(b)

Fig. 11. Quasi-static compressive performance of Ag SLM bone scaffolds showing (a) SC90 and (b) SC68.

It can be seen that as the compression strain increases, the scaffolds were getting plastically deformed (crushed) subsequently undergoing densification. Accordingly, the three distinct regions of the $\sigma-\varepsilon$ curve can be identified as: $(i)$ the linear elastic region followed by (ii) the plateau and finally (iii) densification where a steep rise in stress can be observed. The performance at the plateau region was a result of the interaction between the crushed material. As a result, two distinct slopes can be dictated by the respective porosity of scaffolds being tested. Therefore Fig. 11a is representative of a highly porous structure while Fig. 11b represents a comparatively dense structure characterised by the shorter and steeper plateau region.

Looking at the experimental performance parameters for the pure Ag SLM scaffolds, the highest elastic modulus $\left(E_{\text {exp }}\right)$ was exhibited by SC68 followed by SC90 at 1.86 and $0.13 \mathrm{GPa}$ respectively. This performance trend was anticipated as SC68 features a lower porosity in comparison to SC90 at $68.46 \%$ and $90.69 \%$ respectively. The trend was similar for yield strength $\left(\sigma_{y}\right)$, where SC90 showed the lowest performance at 10.16 MPa and SC68 the highest at 44.58 $\mathrm{MPa}$. Comparing this to the theoretical performance calculated using relative density $\left(E_{r}\right.$ and $\sigma_{r}$ ), the experimental performance was representative of the porosity. Even so, a difference of $5 \%$ and $17 \%$ was observed between both the methods for the elastic modulus and compressive stress respectively at a relative density of 0.32. In comparison at the lower ${ }_{r d}$ of 0.09 , Ashby's model overestimated the elastic modulus by $14 \%$ and compressive strength by $67 \%$. This significant variation between experimental and theoretical performance at the highest porosity of $90.69 \%$ may signify structural anomalies introduced during SLM which is further explored through X-ray nCT. 


\subsubsection{Failure modes}

One of the earliest studies on the effects of AM process-induced imperfections on the mechanical performance of SLM biomaterial lattice structures were studied by Campoli et al. [84]. The study showed that the weak spots in the geometry as a result of SLM substantially reduces the mechanical properties as compared to what was predicted by analytical models. It is important to realise that quality (continuity of the bulk material) of any SLM component depends not only on the process parameters but also on the part orientation with respect to the powder bed $[58,113]$. To investigate this aspect selected still frames recorded under quasi-static compression were analysed as shown in Fig. 12. As can be seen, chosen frames correspond to the compressive strain between $10 \%$ and $60 \%$. From the deformation pattern exhibited by the structures, two distinct failure modes can be identified. Overall, it is clear that the porosity of the scaffolds has a significant effect on the part quality as SC90 clearly shows localised failure.

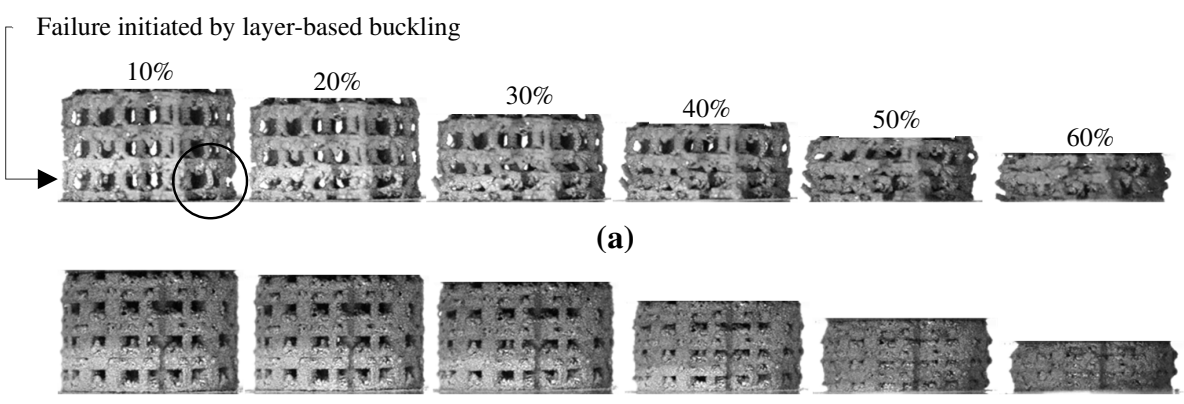

(b)

Fig. 12. Deformation and failure associated with pure Ag scaffold prototypes where (a) shows SC90 and (b) SC68.

Looking at the deformation of SC90 (Fig. 12a), the failure was dominated by weaker links at the lowest layer. As a result, a buckling induced failure can be observed starting from the first layer where multiple weaker links buckles to initiate plastic failure. To identify the reason for this localised failure, X-ray nCT of the scaffolds was conducted as shown in Fig. 13. This data helps to determine any manufacturing defects that may have been induced during SLM. It is clear from Fig. 13b that an SLM induced geometrical irregularity exists acting as a weak link at the first layer of SC90. The location of the link in Fig. 13b corresponds with the failed band and buckled beams explaining the failure modes observed as shown in Fig. 12a.

In addition to mechanical performance, the failure mechanism of SLM materials is dependant not only on the process parameters but also on the porosity and thickness of the struts. Most importantly thin-walled geometries are more prone to SLM induced defects compared to thickwalled structures. When it comes to the low porosity variant SC68, Fig. 13a shows that the scaffold prototype has good structural integrity and as a result shows failure due to barrel-shaped bulging (Fig. 12b) as opposed to localised failure. The X-ray nCT data reveals a dense part which is performing close to theoretical prediction. This shows that while laser melting pure $\mathrm{Ag}$ 
using the process parameters reported, the unit cell porosity and wall thickness has a significant impact on the mechanical performance. Consequently, further refinement of the process parameters and powder characteristics are required to conceive geometrically accurate parts $<300 \mu \mathrm{m}$ at $90 \%$ porosity. However, the parameters presented in this paper are capable of manufacturing highly repeatable and geometrically precise parts for beam/wall thicknesses above $300 \mu \mathrm{m}$ up to porosity of $\sim 70 \%$.

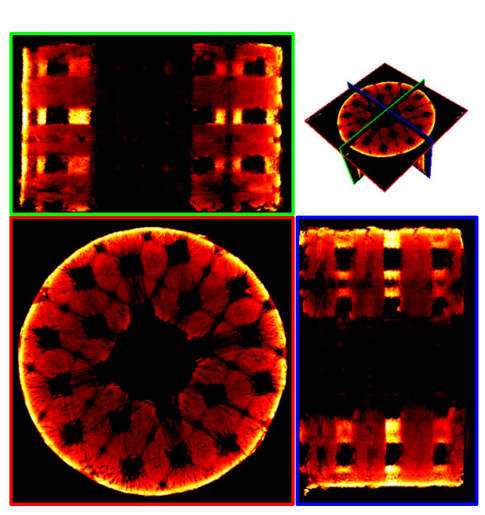

(a)

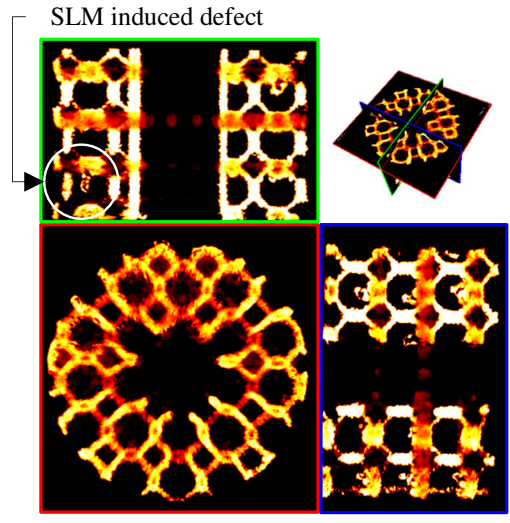

(b)

Fig. 13. Reconstructed X-ray nCT data of the SLM pure Ag scaffolds showing (a) SC68 and (b) SC90.

\subsubsection{Chemical composition and morphology}

According to Weber [114] micro/nano characteristics such as surface roughness, topology, and pore interconnectivity are important parameters for bone-interfacing scaffolds and hence influence osseointegration. Therefore, in addition to mechanical properties such as elastic modulus and strength, the surface itself has to provide the vital interconnectedness suitable for the migration and proliferation of osteoprogenitor cells or nucleation sites for de novo bone formation within the scaffold. To this end, the Ag scaffolds were SEM analysed to study the surface properties as shown in Fig. 14. While the figure shows the existence of multiple open porosities that allows for osteoblast incubation, the EDS analysis showed the presence of higher oxygen for areas identified by spectrum 2 as listed in Table 5. Looking at the data, these scattered areas of higher oxygen content can be identified as shown in Fig. 14b, which looks like spatter and oxidation reactions occurring at the laser melting course.

Looking closely at the melt pool during melting and solidification of pure $\mathrm{Ag}$ is critical to comprehend the reason for the presence of oxygen spatter. The EDS data shows that some Ag spatter was enriched with surface oxides resulting in a higher content of oxygen residue. According to Das [98], the stability of the melt pool and the melting itself depends largely on oxide formed as a result of laser melting. From this perspective, considering the $\mathrm{O} 2$ (diatomic oxygen) partial pressure at the laser melting environment, it was plausible that the $\sim 962^{\circ} \mathrm{C}$ temperature pure Ag melt pool triggered the oxide film formation on certain spatter. In any 
case, the occurrence of oxygen-enriched spatter was found to be sparse and was identified only on the top and bottom surfaces of the scaffold parallel to the powder bed.

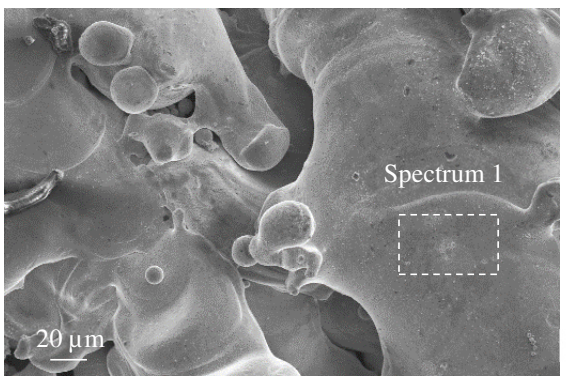

(a)

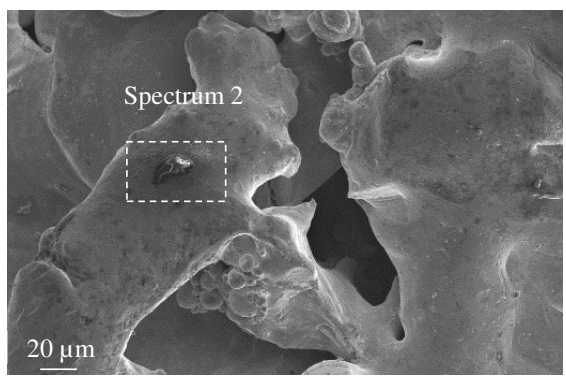

(b)

Fig. 14. Surface morphology of the scaffold walls showing the respective sections used for EDS analysis where (a) shows SC68 and (b) SC90.

Table 5. Elemental composition derived from EDS spectrum of the respective regions as shown in Fig. 14.

\begin{tabular}{ccccc}
\hline \multirow{2}{*}{ Element } & \multicolumn{2}{c}{ Spectrum 1 } & \multicolumn{2}{c}{ Spectrum 2 } \\
\cline { 2 - 5 } & Weight $\%$ & Atomic\% & Weight\% & Atomic\% \\
\hline O & 0.73 & 4.75 & 5.80 & 29.35 \\
$\mathrm{Ag}$ & 99.27 & 95.25 & 94.20 & 70.65 \\
Total & 100 & 100 & 100 & 100 \\
\hline
\end{tabular}

To put these observations into perspective, Louvis et al. [115] suggest that oxide layers generally found on metals such as aluminium are also stirred at the melt pool, however, the subsequent effects are negligible. The reason for this according to Verhaeghe et al. [116] was that the SLM process does not vaporise thicker oxides layers present in these materials due to the limited energy density. Overall, little has been studied on material evaporation during powder bed fusion. Nevertheless, studies conducted on laser welding shows that evaporation influences laser absorption, which in turn gives rise to fumes that were deposited on the component as oxygenenriched laser spatter $[117,118]$. This shows that further optimisation of the chamber environment is required to reduce oxygen contamination. However, this change was primarily present on the surface alone and no change in elemental composition or Ag phase change was observed at the melt pool. These spatter spots can also be removed through effective postprocessing such as abrasive blasting before implantation.

The mean surface roughness of the as-built pure Ag scaffold measured across the surface boundaries was found to be $51.4 \mu \mathrm{m}$. Any unmelted or loose particles on the scaffolds were removed through post-processing by sandblasting followed by cleaning with compressed air. The surface roughness characterisation of the scaffolds was characterised following the postprocessing. A rough surface finish was exhibited by SLM scaffolds as a result of partially molten $\mathrm{Ag}$ particles that were attached to the surface. In addition, the laser scan marks characteristic of the SLM process representative of the layer-by-layer manufacturing were also identified. 
Previous work [119] show that surface roughness of $40 \mu \mathrm{m}$ is effective in accommodating osteoblasts responsible for bone growth. Even so, it is worth noting that osteoblasts come in numerous sizes and mature osteoblasts can grow over $200 \mu \mathrm{m}$. Therefore, the combination of small pores facilitated by the rough surface combined with geometrical porosity satisfies the requirements for osseointegration.

\subsubsection{Antimicrobial property}

When it comes to strategies for the inclusion of antimicrobial properties into orthopaedic implants, a large proportion of the research experiments with metallic ions such as copper, silver, and zinc. The existing data $[52,120,121]$ on these materials show that they offer broad-spectrum antimicrobial properties suitable for infection resistance. According to Croes et al. [121] amongst all of these different materials, $\mathrm{Ag}$ is the most promising as it features well-established antimicrobial properties and offers low cytotoxicity to osteoblast responsible for bone regeneration. The mechanism of antimicrobial response in Ag involves two primary phases: In the first phase $\mathrm{Ag}$ ions binds with the bacterial membrane causing damage resulting in the condensation of deoxyribonucleic acid (DNA); in the second phase the penetrated membrane generated 'reactive oxygen species' (ROS) exerts oxidative stress further extending the antimicrobial capacity.

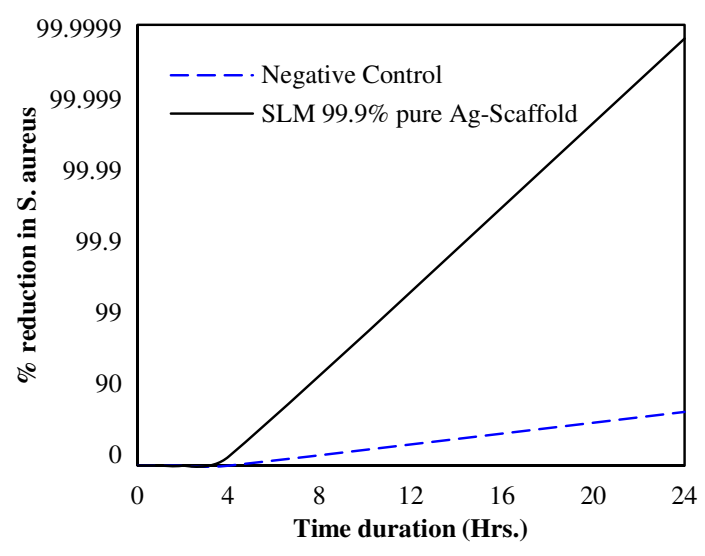

Fig. 15. Antibacterial time-kill efficacy of additively manufactured pure Ag bone scaffold against S. aureus.

Nevertheless, it is worth noting that so far the studies on establishing antimicrobial properties on implants either feature porous implants loaded with Ag nanoparticles [25] or specialist biofunctionalised Ag coatings [28,59,122]. While these routes offer the potential for developing targeted antimicrobial treatments and implants, they do extend the time, cost, and complexity of the manufacturing process itself. In this regard, an alternative route that allows the direct additive manufacturing of $\mathrm{Ag}$ influenced antimicrobial scaffolds suitable for on-demand implants is warranted. To this extent, there is no information on the antibacterial performance of laser melted 99.9\% pure Ag. Therefore to confirm whether the SLM pure Ag scaffold possesses any antibacterial efficacy; the material was investigated on Staphylococcus aureus (ATCC6538). 
According to Jaurugei et al. [123], S. aureus is one of the most common infections causing bacterium in scaffolds. It falls under the Gram-positive classification which is associated with large amounts of soft tissue infections in humans. Infections as a result of Gram-positive bacteria are susceptible to beta-lactam antibiotics like penicillin meaning they have a high efficacy in acquiring antibiotic resistance (an example of this is the superbug MRSA which is a staphylococcus species). Although S. aureus infections can often be treated, when associated with scaffold they lead to invasive and life-threatening complications.

Besides, hospital-acquired S. aureus infections are further complicated as a result of the multidrug-resistance nature of the strains. They have also been reported to affect medical devices creating biofilms in vivo which further contributed to implant-associated infection [124-126]. According to Johnson et al. [127], even though there are other types of microbes that are capable of implant infections, S. aureus is one of the most common pathogens. Therefore, as an initial test to inform the infection-resistance of the additively manufactured SLM pure-Ag, a 24-hour time-kill experiment was carried out on S. aureus. Two SLM pure-Ag samples were investigated and the reduction in viable cells was plotted as the change in log viability for each time point compared to zero-time viability. An identical test was carried out on Dulbecco's Phosphate Buffered Saline (DPBS) as a negative control to fully associate the observance of any antibacterial activities to the scaffold alone.

The antibacterial analysis shown in Fig. 15 confirms that the laser melted pure-Ag scaffolds not only inhibits the growth but kills S. aureus bacterium that is commonly associated with biofilm formation and implant-related infection. It can be seen that the antibacterial activity of the scaffold starts around 4 hours and leads to a $90 \%$ reduction of S. aureus in 7 hours. Overall, a 99.9\% reduction in S. aureus was achieved by the scaffold in 14 hours showing that the SLM

pure Ag scaffolds show antibacterial efficacy validating the direction of the study. However, it is unclear whether the antimicrobial activities of SLM Ag are exclusively mediated by the release of silver ions $(\mathrm{Ag}+)$ or, instead, are due to a combination of surface and silver ion effects. This aspect needs further investigation.

This is the first study on the SLM of pure silver, consequently, the intention is not for it to be used as a standalone biomaterial. Rather, it is a first step in the development of a new class of antibacterial biomaterials that can be additively manufactured which does not require extensive post-processing such as coating. It is anticipated that the effective understanding of SLM parameters and the performance of pure $\mathrm{Ag}$ will accelerate the development of functional $\mathrm{Ag}$ alloys that delivers a good balance between mechanical, antimicrobial, and osteogenic properties.

\section{Conclusion}

Implant related infection is a serious concern and various research efforts are going on around the world to address this issue. To this extent, this study demonstrates the use of selective laser 
melting to fabricate porous (68-90\%) Ag bone scaffolds with antibacterial properties and reports the respective processing parameters for the first time. The morphological evaluation of laser melted pure Ag shows that the process parameters reported can deliver a relative density of 97\%. The material exhibits Young's modulus and yield strength of $17.8 \mathrm{GPa}$ and $67.15 \mathrm{MPa}$ respectively when printed at a scan speed, hatch distance, and layer thickness of $800 \mathrm{~mm} / \mathrm{s}$, $0.16 \mathrm{~mm}$ and $0.3 \mu \mathrm{m}$ respectively using a $370 \mathrm{~W}$ laser system. Nevertheless, the X-ray nCT scan analysis revealed the presence of porosity defect, which contributed to the fracture mechanics of the tensile coupon. A high localised stress concentration facilitated by the pre-existing microvoids was the reason for the observed semi-ductile behaviour and the associated mechanical performance. The subsequently developed low (68\%) and high (90\%) porosity pure Ag bone scaffolds exhibited the yield strength and elastic modulus in the range of 44.58-10.16 MPa and 1.86-0.13 GPa. For the $68 \%$ porous scaffold, the theoretical prediction was conservative and underestimated Young's modulus and compressive strength by $5 \%$ and $17 \%$ respectively. However, at lower $r_{r}$ of 0.09 , the theoretical calculation overestimated the elastic modulus by $14 \%$ and compressive strength by $67 \%$. This significant variation between experimental and theoretical performance at the highest porosity of $90.69 \%$ was identified using X-ray nCT analysis as the result of porosity defects introduced during SLM process. Nevertheless, with a yield strength of $44.58 \mathrm{MPa}$, an elastic modulus of $1.86 \mathrm{GPa}$, and a ductile deformation mechanism at $68 \%$ porosity, SLM pure Ag scaffold exhibits mechanical properties that are in the range of cancellous bone. While EDS analysis showed a $5.8 \%$ oxygen contamination at the surfaces of the pure Ag scaffolds, the antibacterial efficacy was unaffected. The SLM pure-Ag scaffold not only inhibited the bacterial growth but showed a $99.9 \%$ kill of the most common implant infection-causing Staphylococcus aureus in 14 hours. Overall, the study shows that SLM powder bed fusion is suitable to fabricate porous Ag bone scaffolds with interesting mechanical behaviour and promising antibacterial efficacy.

\section{Acknowledgement}

This project was supported by both University of Wolverhampton and 6DMe Ltd. UK.

\section{References}

[1] E.F. DiCarlo, L.B. Kahn, Inflammatory diseases of the bones and joints, Semin. Diagn. Pathol. 28 (2011) 53-64. https://doi.org/10.1053/j.semdp.2011.02.012.

[2] W. Zhang, H. Ouyang, C.R. Dass, J. Xu, Current research on pharmacologic and regenerative therapies for osteoarthritis, Bone Res. 4 (2016) 15040. https://doi.org/10.1038/boneres.2015.40.

[3] M. Ribeiro, F.J. Monteiro, M.P. Ferraz, Infection of orthopedic implants with emphasis on bacterial adhesion process and techniques used in studying bacterial-material interactions, (n.d.). https://doi.org/10.4161/biom.22905.

[4] M. Navarro, A. Michiardi, O. Castaño, J.A. Planell, Biomaterials in orthopaedics, J. R. Soc. Interface. 5 (2008) 1137-1158. https://doi.org/10.1098/rsif.2008.0151.

[5] Y.-Q. Xu, Y.-L. Zhu, X.-Y. Fan, T. Jin, Y. Li, X.-Q. He, Implant-Related Infection in the Tibia: Surgical 
Revision Strategy with Vancomycin Cement, Sci. World J. 2014 (2014) 124864.

https://doi.org/10.1155/2014/124864.

[6] E. O'Cearbhaill, Shedding light on implant-associated infection, Sci. Transl. Med. 11 (2019). https://doi.org/10.1126/scitranslmed.aaz3709.

[7] S.M. Kurtz, E. Lau, H. Watson, J.K. Schmier, J. Parvizi, Economic burden of periprosthetic joint infection in the united states, J. Arthroplasty. 27 (2012) 61-5.e1. https://doi.org/10.1016/j.arth.2012.02.022.

[8] C. Koyama, M. Hirota, Y. Okamoto, T. Iwai, T. Ogawa, T. Hayakawa, K. Mitsudo, A nitrogen-containing bisphosphonate inhibits osteoblast attachment and impairs bone healing in bone-compatible scaffold, J. Mech. Behav. Biomed. Mater. 104 (2020). https://doi.org/10.1016/j.jmbbm.2020.103635.

[9] S. Ma, Q. Tang, Q. Feng, J. Song, X. Han, F. Guo, Mechanical behaviours and mass transport properties of bone-mimicking scaffolds consisted of gyroid structures manufactured using selective laser melting, J. Mech. Behav. Biomed. Mater. 93 (2019) 158-169. https://doi.org/10.1016/j.jmbbm.2019.01.023.

[10] R. Pecci, S. Baiguera, P. Ioppolo, R. Bedini, C. Del Gaudio, 3D printed scaffolds with random microarchitecture for bone tissue engineering applications: Manufacturing and characterization, J. Mech. Behav. Biomed. Mater. 103 (2020). https://doi.org/10.1016/j.jmbbm.2019.103583.

[11] Y. Zamani, G. Amoabediny, J. Mohammadi, H. Seddiqi, M.N. Helder, B. Zandieh-Doulabi, J. Klein-Nulend, J.H. Koolstra, 3D-printed poly(E-caprolactone) scaffold with gradient mechanical properties according to force distribution in the mandible for mandibular bone tissue engineering, J. Mech. Behav. Biomed. Mater. 104 (2020). https://doi.org/10.1016/j.jmbbm.2020.103638.

[12] A. Sharipova, I. Gotman, S.G. Psakhie, E.Y. Gutmanas, Biodegradable nanocomposite Fe-Ag load-bearing scaffolds for bone healing, J. Mech. Behav. Biomed. Mater. 98 (2019) 246-254.

https://doi.org/10.1016/j.jmbbm.2019.06.033.

[13] M. Alksne, M. Kalvaityte, E. Simoliunas, I. Rinkunaite, I. Gendviliene, J. Locs, V. Rutkunas, V. Bukelskiene, In vitro comparison of 3D printed polylactic acid/hydroxyapatite and polylactic acid/bioglass composite scaffolds: Insights into materials for bone regeneration, J. Mech. Behav. Biomed. Mater. 104 (2020). https://doi.org/10.1016/j.jmbbm.2020.103641.

[14] S. Bose, S. Vahabzadeh, A. Bandyopadhyay, Bone tissue engineering using 3D printing, Mater. Today. 16 (2013) 496-504. https://doi.org/10.1016/j.mattod.2013.11.017.

[15] H.E. Burton, N.M. Eisenstein, B.M. Lawless, P. Jamshidi, M.A. Segarra, O. Addison, D.E.T. Shepherd, M.M. Attallah, L.M. Grover, S.C. Cox, The design of additively manufactured lattices to increase the functionality of medical implants, Mater. Sci. Eng. C. 94 (2019) 901-908.

https://doi.org/10.1016/j.msec.2018.10.052.

[16] S. Affatato, F. Foroni, M. Merola, F. Baldacci, Preliminary results of the tribological performance of new modular temporary knee spacer antibiotic-impregnated, J. Mech. Behav. Biomed. Mater. 95 (2019) 205-209. https://doi.org/https://doi.org/10.1016/j.jmbbm.2019.04.009.

[17] A. Sharipova, S.K. Swain, I. Gotman, D. Starosvetsky, S.G. Psakhie, R. Unger, E.Y. Gutmanas, Mechanical, degradation and drug-release behavior of nano-grained Fe-Ag composites for biomedical applications, J. Mech. Behav. Biomed. Mater. 86 (2018) 240-249.

https://doi.org/10.1016/j.jmbbm.2018.06.037.

[18] P. Krakhmalev, I. Yadroitsev, I. Yadroitsava, O. de Smidt, Functionalization of biomedical Ti6Al4V via in situ alloying by $\mathrm{Cu}$ during laser powder bed fusion manufacturing, Materials (Basel). 10 (2017).

https://doi.org/10.3390/ma10101154.

[19] A. Macpherson, X. Li, P. McCormick, L. Ren, K. Yang, T.B. Sercombe, Antibacterial Titanium Produced Using Selective Laser Melting, JOM. 69 (2017) 2719-2724. https://doi.org/10.1007/s11837-017-2589-y.

[20] A.S. Praveen, A. Arjunan, Effect of nano-Al2O3 addition on the microstructure and erosion wear of HVOF 
sprayed NiCrSiB coatings, Mater. Res. Express. 7 (2019) 015006. https://doi.org/10.1088/20531591/ab5bda.

[21] A.S. Praveen, A. Arjunan, Parametric optimisation of High-Velocity Oxy-Fuel Nickel-Chromium-SiliconBoron and Aluminium-Oxide coating to improve erosion wear resistance, Mater. Res. Express. (2019). https://doi.org/10.1088/2053-1591/ab301c.

[22] H. Chouirfa, H. Bouloussa, V. Migonney, C. Falentin-Daudré, Review of titanium surface modification techniques and coatings for antibacterial applications, Acta Biomater. 83 (2019) 37-54. https://doi.org/10.1016/j.actbio.2018.10.036.

[23] W. Orapiriyakul, P.S. Young, L. Damiati, P.M. Tsimbouri, Antibacterial surface modification of titanium implants in orthopaedics, J. Tissue Eng. 9 (2018) 204173141878983. https://doi.org/10.1177/2041731418789838.

[24] J. Vaithilingam, S. Kilsby, R.D. Goodridge, S.D.R. Christie, S. Edmondson, R.J.M. Hague, Immobilisation of an antibacterial drug to Ti6Al4V components fabricated using selective laser melting, Appl. Surf. Sci. 314 (2014) 642-654. https://doi.org/10.1016/j.apsusc.2014.06.014.

[25] Z. Jia, P. Xiu, P. Xiong, W. Zhou, Y. Cheng, S. Wei, Y. Zheng, T. Xi, H. Cai, Z. Liu, C. Wang, W. Zhang, Z. Li, Additively Manufactured Macroporous Titanium with Silver-Releasing Micro-/Nanoporous Surface for Multipurpose Infection Control and Bone Repair - A Proof of Concept, ACS Appl. Mater. Interfaces. 8 (2016) 28495-28510. https://doi.org/10.1021/acsami.6b10473.

[26] C.L. Romanò, H. Tsuchiya, I. Morelli, A.G. Battaglia, L. Drago, Antibacterial coating of implants: are we missing something?, Bone Joint Res. 8 (2019) 199-206. https://doi.org/10.1302/2046-3758.85.BJR-20180316 .

[27] Z. Jia, W. Zhou, J. Yan, P. Xiong, H. Guo, Y. Cheng, Y. Zheng, Constructing Multilayer Silk Protein/Nanosilver Biofunctionalized Hierarchically Structured 3D Printed Ti6Al4 v Scaffold for Repair of Infective Bone Defects, ACS Biomater. Sci. Eng. 5 (2018) 244-261.

https://doi.org/10.1021/acsbiomaterials.8b00857.

[28] S. Amin Yavari, L. Loozen, F.L. Paganelli, S. Bakhshandeh, K. Lietaert, J.A. Groot, A.C. Fluit, C.H.E.E. Boel, J. Alblas, H.C. Vogely, H. Weinans, A.A. Zadpoor, Antibacterial Behavior of Additively Manufactured Porous Titanium with Nanotubular Surfaces Releasing Silver Ions, ACS Appl. Mater. Interfaces. 8 (2016) 17080-17089. https://doi.org/10.1021/acsami.6b03152.

[29] B. Tian, W. Chen, D. Yu, Y. Lei, Q. Ke, Y. Guo, Z. Zhu, Fabrication of silver nanoparticle-doped hydroxyapatite coatings with oriented block arrays for enhancing bactericidal effect and osteoinductivity, J. Mech. Behav. Biomed. Mater. 61 (2016) 345-359. https://doi.org/10.1016/j.jmbbm.2016.04.002.

[30] W. Yee, G. Selvaduray, B. Hawkins, Characterization of silver nanoparticle-infused tissue adhesive for ophthalmic use, J. Mech. Behav. Biomed. Mater. 55 (2016) 67-74.

https://doi.org/10.1016/j.jmbbm.2015.10.011.

[31] Y. Li, P. Pavanram, J. Zhou, K. Lietaert, P. Taheri, W. Li, H. San, M.A. Leeflang, J.M.C. Mol, H. Jahr, A.A. Zadpoor, Additively manufactured biodegradable porous zinc, Acta Biomater. 101 (2020) 609-623. https://doi.org/10.1016/j.actbio.2019.10.034.

[32] C. Mas-Moruno, B. Su, M.J. Dalby, Multifunctional Coatings and Nanotopographies: Toward Cell Instructive and Antibacterial Implants, Adv. Healthc. Mater. 8 (2019) 1801103. https://doi.org/10.1002/adhm.201801103.

[33] M.F. Gutiérrez, J. Bermudez, A. Dávila-Sánchez, L.F. Alegría-Acevedo, L. Méndez-Bauer, M. Hernández, J. Astorga, A. Reis, A.D. Loguercio, P. V. Farago, E. Fernández, Zinc oxide and copper nanoparticles addition in universal adhesive systems improve interface stability on caries-affected dentin, J. Mech. Behav. Biomed. Mater. 100 (2019) 103366. https://doi.org/10.1016/j.jmbbm.2019.07.024.

[34] S. Horiuchi, M. Hiasa, A. Yasue, K. Sekine, K. Hamada, K. Asaoka, E. Tanaka, Fabrications of zinc- 
releasing biocement combining zinc calcium phosphate to calcium phosphate cement, J. Mech. Behav. Biomed. Mater. 29 (2014) 151-160. https://doi.org/10.1016/j.jmbbm.2013.09.005.

[35] R. Hang, A. Gao, X. Huang, X. Wang, X. Zhang, L. Qin, B. Tang, Antibacterial activity and cytocompatibility of Cu-Ti-O nanotubes, 102 (2014) 1850-1858. https://doi.org/10.1002/jbm.a.34847.

[36] N. Sasani, J. Vahdati Khaki, S. Mojtaba Zebarjad, Characterization and nanomechanical properties of novel dental implant coatings containing copper decorated-carbon nanotubes, J. Mech. Behav. Biomed. Mater. 37 (2014) 125-132. https://doi.org/10.1016/j.jmbbm.2014.05.003.

[37] D.D. Kumar, G.S. Kaliaraj, Multifunctional zirconium nitride/copper multilayer coatings on medical grade 316L SS and titanium substrates for biomedical applications, J. Mech. Behav. Biomed. Mater. 77 (2018) 106-115. https://doi.org/10.1016/j.jmbbm.2017.09.007.

[38] M. Fateri, A. Gebhardt, J.-S. Hötter, M. Knothe, F.M. Schmidt, H. Rieper, Numerical and Experimental Investigation of Selective Laser Melting of Silver, Fraunhofer Direct Digit. Manuf. Conf. (DDMC), Berlin. (2012).

[39] K.S. Lim, B.J. Klotz, G.C.J. Lindberg, F.P.W. Melchels, G.J. Hooper, J. Malda, D. Gawlitta, T.B.F. Woodfield, Visible Light Cross-Linking of Gelatin Hydrogels Offers an Enhanced Cell Microenvironment with Improved Light Penetration Depth, Macromol. Biosci. 19 (2019). https://doi.org/10.1002/mabi.201900098.

[40] J. Yan, M.R. Kaizer, Y. Zhang, Load-bearing capacity of lithium disilicate and ultra-translucent zirconias, J. Mech. Behav. Biomed. Mater. 88 (2018) 170-175. https://doi.org/10.1016/j.jmbbm.2018.08.023.

[41] A. Shivaram, S. Bose, A. Bandyopadhyay, Understanding long-term silver release from surface modified porous titanium implants, Acta Biomater. 58 (2017) 550-560. https://doi.org/10.1016/j.actbio.2017.05.048.

[42] V. Edwards-Jones, Antimicrobial and barrier effects of silver against methicillin-resistant Staphylococcus aureus., J. Wound Care. 15 (2006) 285-290. https://doi.org/10.12968/jowc.2006.15.7.26951.

[43] M. Kostakioti, M. Hadjifrangiskou, S.J. Hultgren, Bacterial biofilms: Development, dispersal, and therapeutic strategies in the dawn of the postantibiotic era, Cold Spring Harb. Perspect. Med. 3 (2013). https://doi.org/10.1101/cshperspect.a010306.

[44] J. Li, X. Cui, G.J. Hooper, K.S. Lim, T.B.F. Woodfield, Rational design, bio-functionalization and biological performance of hybrid additive manufactured titanium implants for orthopaedic applications: A review, J. Mech. Behav. Biomed. Mater. 105 (2020) 103671. https://doi.org/10.1016/j.jmbbm.2020.103671.

[45] A. Hasan, G. Waibhaw, V. Saxena, L.M. Pandey, Nano-biocomposite scaffolds of chitosan, carboxymethyl cellulose and silver nanoparticle modified cellulose nanowhiskers for bone tissue engineering applications, Int. J. Biol. Macromol. 111 (2018) 923-934. https://doi.org/10.1016/j.ijbiomac.2018.01.089.

[46] R. Kumar Saini, L. Prasad Bagri, A.K. Bajpai, Nano-silver hydroxyapatite based antibacterial 3D scaffolds of gelatin/alginate/poly (vinyl alcohol) for bone tissue engineering applications, Colloids Surfaces B Biointerfaces. 177 (2019) 211-218. https://doi.org/10.1016/j.colsurfb.2019.01.064.

[47] S. Saravanan, S. Nethala, S. Pattnaik, A. Tripathi, A. Moorthi, N. Selvamurugan, Preparation, characterization and antimicrobial activity of a bio-composite scaffold containing chitosan/nanohydroxyapatite/nano-silver for bone tissue engineering, Int. J. Biol. Macromol. 49 (2011) 188-193. https://doi.org/10.1016/j.ijbiomac.2011.04.010.

[48] W. Guo, W. Liu, L. Xu, P. Feng, Y. Zhang, W. Yang, C. Shuai, Halloysite nanotubes loaded with nano silver for the sustained-release of antibacterial polymer nanocomposite scaffolds, J. Mater. Sci. Technol. 46 (2020) 237-247. https://doi.org/10.1016/j.jmst.2019.11.019.

[49] S. Mondal, T.P. Nguyen, V.H. Pham, G. Hoang, P. Manivasagan, M.H. Kim, S.Y. Nam, J. Oh, Hydroxyapatite nano bioceramics optimized 3D printed poly lactic acid scaffold for bone tissue engineering application, Ceram. Int. 46 (2020) 3443-3455. https://doi.org/10.1016/j.ceramint.2019.10.057. 
[50] H.R. Bakhsheshi-Rad, E. Dayaghi, A.F. Ismail, M. Aziz, A. Akhavan-Farid, X. Chen, Synthesis and invitro characterization of biodegradable porous magnesium-based scaffolds containing silver for bone tissue engineering, Trans. Nonferrous Met. Soc. China (English Ed. 29 (2019) 984-996.

https://doi.org/10.1016/S1003-6326(19)65007-7.

[51] W. Xiong, L. Hao, Y. Li, D. Tang, Q. Cui, Z. Feng, C. Yan, Effect of selective laser melting parameters on morphology, microstructure, densification and mechanical properties of supersaturated silver alloy, Mater. Des. 170 (2019) 107697. https://doi.org/10.1016/j.matdes.2019.107697.

[52] I.A.J. Van Hengel, M. Riool, L.E. Fratila-apachitei, J. Witte-bouma, E. Farrell, A.A. Zadpoor, S.A.J. Zaat, I. Apachitei, Selective laser melting porous metallic implants with immobilized silver nanoparticles kill and prevent biofilm formation by methicillin-resistant Staphylococcus aureus, Biomaterials. (2017). https://doi.org/10.1016/j.biomaterials.2017.02.030.

[53] J. Robinson, M. Stanford, A. Arjunan, Stable Formation of Powder Bed Laser Fused 99.9\% Silver, Mater. Today Commun. (2020) 101195. https://doi.org/10.1016/j.mtcomm.2020.101195.

[54] J. Noh, J. Ha, D. Kim, Femtosecond and nanosecond laser sintering of silver nanoparticles on a flexible substrate, Appl. Surf. Sci. 511 (2020) 145574. https://doi.org/10.1016/j.apsusc.2020.145574.

[55] Y. Qing, K. Li, D. Li, Y. Qin, Antibacterial effects of silver incorporated zeolite coatings on 3D printed porous stainless steels, Mater. Sci. Eng. C. 108 (2020) 110430. https://doi.org/10.1016/j.msec.2019.110430.

[56] X. Wang, J. Liu, L. Yang, Y. He, Y. Wang, Nano-sized amorphous carbon covered surface formed by selective laser melting of ink-printed (SLM-IP) copper (Cu) nanoparticles (NPs), Appl. Surf. Sci. 448 (2018) 133-137. https://doi.org/10.1016/j.apsusc.2018.04.109.

[57] W. Feng, J.N. Tey, Y.C. Wan, X. Shan, H. Zheng, Laser patterning of printed silver for selective lighting of electroluminescence film, J. Manuf. Process. 38 (2019) 445-452.

https://doi.org/10.1016/j.jmapro.2019.01.036.

[58] R. Wauthle, J. Van Der Stok, S.A. Yavari, J. Van Humbeeck, J.P. Kruth, A.A. Zadpoor, H. Weinans, M. Mulier, J. Schrooten, Additively manufactured porous tantalum implants, Acta Biomater. 14 (2015) 217225. https://doi.org/10.1016/j.actbio.2014.12.003.

[59] S. Bakhshandeh, Z. Gorgin Karaji, K. Lietaert, A.C. Fluit, C.H.E. Boel, H.C. Vogely, T. Vermonden, W.E. Hennink, H. Weinans, A.A. Zadpoor, S. Amin Yavari, Simultaneous Delivery of Multiple Antibacterial Agents from Additively Manufactured Porous Biomaterials to Fully Eradicate Planktonic and Adherent Staphylococcus aureus, ACS Appl. Mater. Interfaces. 9 (2017) 25691-25699.

https://doi.org/10.1021/acsami.7b04950.

[60] T. Hanawa, Overview of metals and applications, in: Met. Biomed. Devices, Elsevier Ltd, 2010: pp. 3-24. https://doi.org/10.1533/9781845699246.1.3.

[61] K. Bari, A. Arjunan, Extra low interstitial titanium based fully porous morphological bone scaffolds manufactured using selective laser melting, J. Mech. Behav. Biomed. Mater. 95 (2019) 1-12. https://doi.org/10.1016/j.jmbbm.2019.03.025.

[62] E.I. Zamulaeva, A.N. Sheveyko, A.Y. Potanin, I.Y. Zhitnyak, N.A. Gloushankova, I. V. Sukhorukova, N. V. Shvindina, S.G. Ignatov, E.A. Levashov, D. V. Shtansky, Comparative investigation of antibacterial yet biocompatible Ag-doped multicomponent coatings obtained by pulsed electrospark deposition and its combination with ion implantation, Ceram. Int. 44 (2018) 3765-3774.

https://doi.org/10.1016/j.ceramint.2017.11.160.

[63] R. Liang, Y. Xu, M. Zhao, G. Han, J. Li, W. Wu, M. Dong, J. Yang, Y. Liu, Properties of silver contained coatings on CoCr alloys prepared by vacuum plasma spraying, Mater. Sci. Eng. C. 106 (2020) 110156. https://doi.org/10.1016/j.msec.2019.110156.

[64] A. Arjunan, M. Demetriou, A. Baroutaji, C. Wang, Mechanical performance of highly permeable laser melted Ti6Al4V bone scaffolds, J. Mech. Behav. Biomed. Mater. 102 (2020). 
https://doi.org/10.1016/j.jmbbm.2019.103517.

[65] A. Vance, K. Bari, A. Arjunan, Investigation of Ti64 sheathed cellular anatomical structure as a tibia implant, Biomed. Phys. Eng. Express. 5 (2019) 035008. https://doi.org/10.1088/2057-1976/ab0bd7.

[66] A. Vance, K. Bari, A. Arjunan, Compressive performance of an arbitrary stiffness matched anatomical Ti64 implant manufactured using Direct Metal Laser Sintering, Mater. Des. 160 (2018) 1281-1294. https://doi.org/10.1016/j.matdes.2018.11.005.

[67] A. Arjunan, M. Singh, A. Baroutaji, C. Wang, Additively manufactured AlSi10Mg inherently stable thin and thick-walled lattice with negative Poisson's ratio, Compos. Struct. (2020) 112469.

https://doi.org/10.1016/j.compstruct.2020.112469.

[68] A. Arjunan, A. Baroutaji, A.S. Praveen, A.G. Olabi, C.J. Wang, Acoustic Performance of Metallic Foams, in: Ref. Modul. Mater. Sci. Mater. Eng., Elsevier, 2019. https://doi.org/10.1016/B978-0-12-803581-8.115619 .

[69] L. Pauksch, S. Hartmann, M. Rohnke, G. Szalay, V. Alt, R. Schnettler, K.S. Lips, Biocompatibility of silver nanoparticles and silver ions in primary human mesenchymal stem cells and osteoblasts, Acta Biomater. 10 (2014) 439-449. https://doi.org/10.1016/j.actbio.2013.09.037.

[70] Z. Kanwal, M.A. Raza, S. Riaz, S. Manzoor, A. Tayyeb, I. Sajid, S. Naseem, Synthesis and characterization of silver nanoparticle-decorated cobalt nanocomposites (Co@AgNPs) and their density-dependent antibacterial activity, R. Soc. Open Sci. 6 (2019) 182135. https://doi.org/10.1098/rsos.182135.

[71] A. Nyga, A. Hart, T.D. Tetley, Importance of the HIF pathway in cobalt nanoparticle-induced cytotoxicity and inflammation in human macrophages, Nanotoxicology. 9 (2015) 905-917.

https://doi.org/10.3109/17435390.2014.991430.

[72] B. Jansen, M. Rinck, P. Wolbring, A. Strohmeier, T. Jahns, In vitro Evaluation of the Antimicrobial Efficacy and Biocompatibility of a Silver-Coated Central Venous Catheter, J. Biomater. Appl. 9 (1994) 5570. https://doi.org/10.1177/088532829400900103.

[73] A. Oloffs, C. Grosse-Siestrup, S. Bisson, M. Rinck, R. Rudolph, U. Gross, Biocompatibility of silver-coated polyurethane catheters and silvercoated Dacron® material, Biomaterials. 15 (1994) 753-758.

https://doi.org/10.1016/0142-9612(94)90028-0.

[74] J.A. Spadaro, S.E. Chase, D.A. Webster, Bacterial inhibition by electrical activation of percutaneous silver implants, J. Biomed. Mater. Res. 20 (1986) 565-577. https://doi.org/10.1002/jbm.820200504.

[75] C.C. Chu, W.C. Tsai, J.Y. Yao, S.S. Chiu, Newly made antibacterial braided nylon sutures. I. In vitro qualitative and in vivo preliminary biocompatibility study, J. Biomed. Mater. Res. 21 (1987) 1281-1300. https://doi.org/10.1002/jbm.820211102.

[76] R. Zhang, P. Lee, V.C.H. Lui, Y. Chen, X. Liu, C.N. Lok, M. To, K.W.K. Yeung, K.K.Y. Wong, Silver nanoparticles promote osteogenesis of mesenchymal stem cells and improve bone fracture healing in osteogenesis mechanism mouse model, Nanomedicine Nanotechnology, Biol. Med. 11 (2015) 1949-1959. https://doi.org/10.1016/j.nano.2015.07.016.

[77] J. Tian, K.K.Y. Wong, C.M. Ho, C.N. Lok, W.Y. Yu, C.M. Che, J.F. Chiu, P.K.H. Tam, Topical delivery of silver nanoparticles promotes wound healing, ChemMedChem. 2 (2007) 129-136.

https://doi.org/10.1002/cmdc.200600171.

[78] X. Liu, P.Y. Lee, C.M. Ho, V.C.H. Lui, Y. Chen, C.M. Che, P.K.H. Tam, K.K.Y. Wong, Silver nanoparticles mediate differential responses in keratinocytes and fibroblasts during skin wound healing, ChemMedChem. 5 (2010) 468-475. https://doi.org/10.1002/cmdc.200900502.

[79] K.H.L. Kwan, X. Liu, M.K.T. To, K.W.K. Yeung, C. ming Ho, K.K.Y. Wong, Modulation of collagen alignment by silver nanoparticles results in better mechanical properties in wound healing, Nanomedicine Nanotechnology, Biol. Med. 7 (2011) 497-504. https://doi.org/10.1016/j.nano.2011.01.003. 
[80] A. du Plessis, I. Yadroitsava, I. Yadroitsev, Effects of defects on mechanical properties in metal additive manufacturing: A review focusing on X-ray tomography insights, Mater. Des. 187 (2020) 108385. https://doi.org/10.1016/j.matdes.2019.108385.

[81] ISO 7500-1:2018 - Metallic materials -- Calibration and verification of static uniaxial testing machines -Part 1: Tension/compression testing machines -- Calibration and verification of the force-measuring system, 2018. https://www.iso.org/standard/72572.html (accessed January 28, 2019).

[82] K. Li, K. Cai, Q. Ran, D. Jiang, Biomimetic triphase composite scaffolds with antibacterial and anti-tumor potentials for bone repair, Mater. Lett. 256 (2019) 126590. https://doi.org/10.1016/j.matlet.2019.126590.

[83] D. Agius, K.I. Kourousis, C. Wallbrink, D. Agius, K.I. Kourousis, C. Wallbrink, A Review of the As-Built SLM Ti-6Al-4V Mechanical Properties towards Achieving Fatigue Resistant Designs, Metals (Basel). 8 (2018) 75. https://doi.org/10.3390/met8010075.

[84] G. Campoli, M.S.S. Borleffs, S. Amin Yavari, R. Wauthle, H. Weinans, A.A.A. Zadpoor, Mechanical properties of open-cell metallic biomaterials manufactured using additive manufacturing, Mater. Des. 49 (2013) 957-965. https://doi.org/10.1016/j.matdes.2013.01.071.

[85] P.H. Warnke, T. Douglas, P. Wollny, E. Sherry, M. Steiner, S. Galonska, S.T. Becker, I.N. Springer, J. Wiltfang, S. Sivananthan, Rapid Prototyping: Porous Titanium Alloy Scaffolds Produced by Selective Laser Melting for Bone Tissue Engineering, Tissue Eng. Part C Methods. 15 (2009) 115-124. https://doi.org/10.1089/ten.tec.2008.0288.

[86] M. Colopi, L. Caprio, A.G.G. Demir, B. Previtali, Selective laser melting of pure Cu with a $1 \mathrm{~kW}$ single mode fiber laser, 2018. https://www.sciencedirect.com/science/article/pii/S221282711830814X (accessed January 19, 2019).

[87] K. Deprez, S. Vandenberghe, K. Van Audenhaege, J. Van Vaerenbergh, R. Van Holen, Rapid additive manufacturing of MR compatible multipinhole collimators with selective laser melting of tungsten powder, Med. Phys. 40 (2013) 012501. https://doi.org/10.1118/1.4769122.

[88] B. Zhang, H. Liao, C. Coddet, Effects of processing parameters on properties of selective laser melting Mg9\% Al powder mixture, Mater. Des. 34 (2012) 753-758. https://doi.org/10.1016/j.matdes.2011.06.061.

[89] M. Khan, P. Dickens, Selective Laser Melting (SLM) of pure gold, Gold Bull. 43 (2010) 114-121. https://doi.org/10.1007/BF03214976.

[90] M. Yakout, M.A. Elbestawi, S.C. Veldhuis, Density and mechanical properties in selective laser melting of Invar 36 and stainless steel 316L, J. Mater. Process. Technol. 266 (2019) 397-420. https://doi.org/10.1016/J.JMATPROTEC.2018.11.006.

[91] A.H. Maamoun, Y.F. Xue, M.A. Elbestawi, S.C. Veldhuis, A.H. Maamoun, Y.F. Xue, M.A. Elbestawi, S.C. Veldhuis, Effect of Selective Laser Melting Process Parameters on the Quality of Al Alloy Parts: Powder Characterization, Density, Surface Roughness, and Dimensional Accuracy, Materials (Basel). 11 (2018) 2343. https://doi.org/10.3390/ma11122343.

[92] J. Ciurana, L. Hernandez, J. Delgado, Energy density analysis on single tracks formed by selective laser melting with CoCrMo powder material, Int. J. Adv. Manuf. Technol. 68 (2013) 1103-1110. https://doi.org/10.1007/s00170-013-4902-4.

[93] N. Read, W. Wang, K. Essa, M.M. Attallah, Selective laser melting of AlSi10Mg alloy: Process optimisation and mechanical properties development, 65 (2015) 417-424. https://doi.org/10.1016/j.matdes.2014.09.044.

[94] T. de Terris, O. Andreau, P. Peyre, F. Adamski, I. Koutiri, C. Gorny, C. Dupuy, Optimization and comparison of porosity rate measurement methods of Selective Laser Melted metallic parts, Addit. Manuf. 28 (2019) 802-813. https://doi.org/10.1016/j.addma.2019.05.035.

[95] N. Li, S. Huang, G. Zhang, R. Qin, W. Liu, H. Xiong, G. Shi, J. Blackburn, Progress in additive manufacturing on new materials: A review, J. Mater. Sci. Technol. 35 (2019) 242-269. 
https://doi.org/10.1016/J.JMST.2018.09.002.

[96] K.S. Munir, Y. Li, C. Wen, Metallic scaffolds manufactured by selective laser melting for biomedical applications, in: Met. Foam Bone Process. Modif. Charact. Prop., Elsevier Inc., 2016: pp. 1-23. https://doi.org/10.1016/B978-0-08-101289-5.00001-9.

[97] C.Y. Yap, C.K. Chua, Z.L. Dong, Z.H. Liu, D.Q. Zhang, L.E. Loh, S.L. Sing, Review of selective laser melting: Materials and applications, Appl. Phys. Rev. 2 (2015) 041101. https://doi.org/10.1063/1.4935926.

[98] S. Das, Physical Aspects of Process Control in Selective Laser Sintering of Metals, John Wiley \& Sons, Ltd, 2003. https://doi.org/10.1002/adem.200310099.

[99] G. Pantazopoulos, A Short Review on Fracture Mechanisms of Mechanical Components Operated under Industrial Process Conditions: Fractographic Analysis and Selected Prevention Strategies, Metals (Basel). 9 (2019) 148. https://doi.org/10.3390/met9020148.

[100] W.D. Callister, D.G. Rethwisch, Materials science and engineering, n.d.

[101] H. Li, M. Fu, Damage Evolution and Ductile Fracture, in: Deform. Process. Mater., Elsevier, 2019: pp. 85136. https://doi.org/10.1016/b978-0-12-814381-0.00003-0.

[102] G. Bai, J. Daan Van Wyk, Low-Temperature Sintering of Nanoscale Silver Paste for Semiconductor Device Interconnection, 2005.

[103] A. Ahmed, A. Majeed, Z. Atta, G. Guozhu, Dimensional Quality and Distortion Analysis of Thin-Walled Alloy Parts of AlSi10Mg Manufactured by Selective Laser Melting, J. Manuf. Mater. Process. 3 (2019) 51. https://doi.org/10.3390/jmmp3020051.

[104] A.A.A.A. Zadpoor, Mechanics of additively manufactured biomaterials, Elsevier Ltd, 2017. https://doi.org/10.1016/j.jmbbm.2017.03.018.

[105] J.H. Tan, W.L.E. Wong, K.W. Dalgarno, An overview of powder granulometry on feedstock and part performance in the selective laser melting process, Addit. Manuf. 18 (2017) 228-255.

https://doi.org/10.1016/j.addma.2017.10.011

[106] V. Weißmann, P. Drescher, R. Bader, H. Seitz, H. Hansmann, N. Laufer, Comparison of Single Ti 6 Al 4 V Struts Made Using Selective Laser Melting and Electron Beam Melting Subject to Part Orientation, Metals (Basel). (2017). https://doi.org/10.3390/met7030091.

[107] F.S.L.S.L. Bobbert, K. Lietaert, A.A.A. Eftekhari, B. Pouran, S.M.M. Ahmadi, H. Weinans, A.A.A. Zadpoor, Additively manufactured metallic porous biomaterials based on minimal surfaces: A unique combination of topological, mechanical, and mass transport properties, Acta Biomater. 53 (2017) 572-584. https://doi.org/10.1016/j.actbio.2017.02.024.

[108] Z.S. Bagheri, D. Melancon, L. Liu, R.B. Johnston, D. Pasini, Compensation strategy to reduce geometry and mechanics mismatches in porous biomaterials built with Selective Laser Melting, J. Mech. Behav. Biomed. Mater. 70 (2017) 17-27. https://doi.org/10.1016/j.jmbbm.2016.04.041.

[109] A.A. Zadpoor, Design for additive bio-manufacturing: From patient-specific medical devices to rationally designed meta-biomaterials, Int. J. Mol. Sci. 18 (2017). https://doi.org/10.3390/ijms18081607.

[110] M.F. Ashby, Y.J.M. Bréchet, Designing hybrid materials, Acta Mater. 51 (2003) 5801-5821. https://doi.org/10.1016/S1359-6454(03)00441-5.

[111] J. Helsen, Y. Missirlis, Biomaterials: A Tantalus Experience, 1st ed., Springer, New York, 2010.

[112] D. Wu, P. Isaksson, S.J. Ferguson, C. Persson, Young's modulus of trabecular bone at the tissue level: A review, Acta Biomater. 78 (2018) 1-12. https://doi.org/10.1016/j.actbio.2018.08.001.

[113] E. Sallica-Leva, A.L. Jardini, J.B. Fogagnolo, Microstructure and mechanical behavior of porous Ti-6Al-4V parts obtained by selective laser melting, J. Mech. Behav. Biomed. Mater. 26 (2013) 98-108. 
https://doi.org/10.1016/j.jmbbm.2013.05.011.

[114] F.E. Weber, Reconsidering Osteoconduction in the Era of Additive Manufacturing, Tissue Eng. Part B Rev. 25 (2019) 375-386. https://doi.org/10.1089/ten.teb.2019.0047.

[115] E. Louvis, P. Fox, C.J. Sutcliffe, Selective laser melting of aluminium components, J. Mater. Process. Technol. 211 (2011) 275-284. https://doi.org/10.1016/j.jmatprotec.2010.09.019.

[116] F. Verhaeghe, T. Craeghs, J. Heulens, L. Pandelaers, A pragmatic model for selective laser melting with evaporation, Acta Mater. 57 (2009) 6006-6012. https://doi.org/10.1016/j.actamat.2009.08.027.

[117] M. Gao, Y. Kawahito, S. Kajii, Observation and understanding in laser welding of pure titanium at subatmospheric pressure, Opt. Express. 25 (2017) 13539. https://doi.org/10.1364/oe.25.013539.

[118] Z. Chen, X. Gao, S. Katayama, Z. Xiao, X. Chen, Elucidation of high-power disk laser welding phenomena by simultaneously observing both top and bottom of weldment, Int. J. Adv. Manuf. Technol. 88 (2017) 1141-1150. https://doi.org/10.1007/s00170-016-8837-4.

[119] W. Bonfield, Designing porous scaffolds for tissue engineering, Philos. Trans. R. Soc. A Math. Phys. Eng. Sci. 364 (2006) 227-232. https://doi.org/10.1098/rsta.2005.1692.

[120] G.T. Hischebeth, T.M. Randau, M.M. Ploeger, M.J. Friedrich, E. Kaup, C. Jacobs, E. Molitor, A. Hoerauf, S. Gravius, M.D. Wimmer, Staphylococcus aureus versus Staphylococcus epidermidis in periprosthetic joint infection - Outcome analysis of methicillin-resistant versus methicillin-susceptible strains, Diagn. Microbiol. Infect. Dis. 93 (2019) 125-130. https://doi.org/10.1016/j.diagmicrobio.2018.08.012.

[121] M. Croes, S. Bakhshandeh, I.A.J. van Hengel, K. Lietaert, K.P.M. van Kessel, B. Pouran, B.C.H. van der Wal, H.C. Vogely, W. Van Hecke, A.C. Fluit, C.H.E. Boel, J. Alblas, A.A. Zadpoor, H. Weinans, S. Amin Yavari, Antibacterial and immunogenic behavior of silver coatings on additively manufactured porous titanium, Acta Biomater. 81 (2018) 315-327. https://doi.org/10.1016/j.actbio.2018.09.051.

[122] M. Wang, Y. Wu, S. Lu, T. Chen, Y. Zhao, H. Chen, Z. Tang, Fabrication and characterization of selective laser melting printed Ti-6Al-4V alloys subjected to heat treatment for customized implants design, Prog. Nat. Sci. Mater. Int. 26 (2016) 671-677. https://doi.org/10.1016/j.pnsc.2016.12.006.

[123] R. Gutierrez Jauregui, H. Fleige, A. Bubke, M. Rohde, S. Weiss, R. Förster, IL-1 $\beta$ Promotes Staphylococcus aureus Biofilms on Implants in vivo, Front. Immunol. 10 (2019) 1082. https://doi.org/10.3389/fimmu.2019.01082.

[124] R. Prabhakara, J.M. Harro, J.G. Leid, M. Harris, M.E. Shirtliff, Murine immune response to a chronic Staphylococcus aureus biofilm infection, Infect. Immun. 79 (2011) 1789-1796. https://doi.org/10.1128/IAI.01386-10.

[125] Y. Zhao, M. Zhou, Y. Gao, H. Liu, W. Yang, J. Yue, D. Chen, Shifted T helper cell polarization in a murine Staphylococcus aureus mastitis model, PLoS One. 10 (2015).

https://doi.org/10.1371/journal.pone.0134797.

[126] R.A. Brady, C.P. Mocca, R.D. Plaut, K. Takeda, D.L. Burns, Comparison of the immune response during acute and chronic Staphylococcus aureus infection, PLoS One. 13 (2018). https://doi.org/10.1371/journal.pone.0195342.

[127] C.T. Johnson, A.J. García, Scaffold-based Anti-infection Strategies in Bone Repair, Ann. Biomed. Eng. 43 (2015) 515-528. https://doi.org/10.1007/s10439-014-1205-3. 